\title{
Plutonium Well Logging with the Photoneutron Uranium Exploration System
}

\author{
Michael P. Baker
}

Thomas Marks

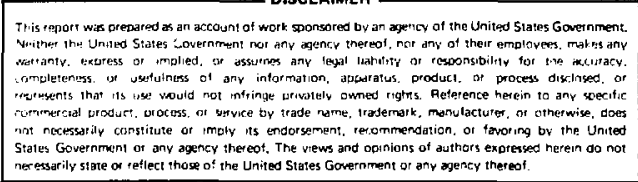




\section{CONTENTS}

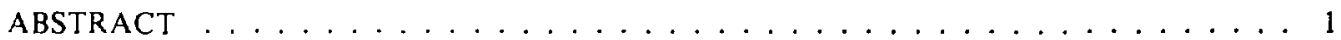

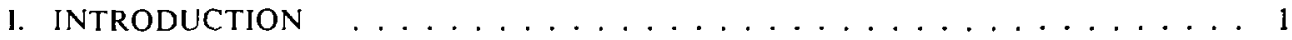

II. PROBE THEORY AND DESCRIPTION $\ldots \ldots \ldots \ldots \ldots \ldots$

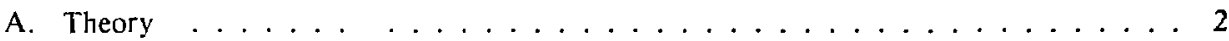

B. Method of Operation ................... 3

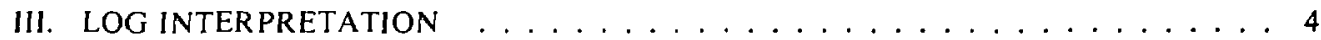

A. Uranium $\log$ Interpretation $\ldots \ldots \ldots \ldots \ldots \ldots \ldots$

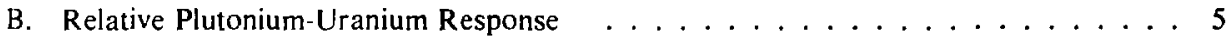

C. Data Interpretation . . . . . . . . . . . . . . . . 6

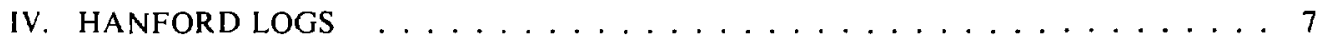

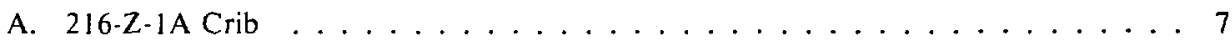

B. Storage Tank Well $(214-Z-361) \ldots \ldots \ldots \ldots \ldots$

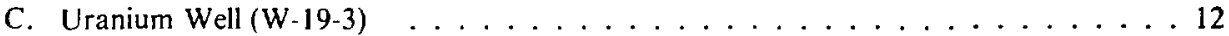

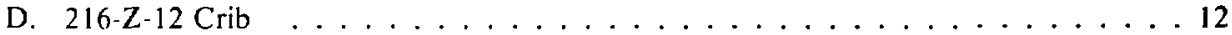

V. CONCLUSIONS AND RECOMMENDATIONS $\ldots \ldots \ldots \ldots \ldots$

ACKNOWLEDGMENTS $\ldots \ldots \ldots \ldots \ldots \ldots \ldots \ldots \ldots$

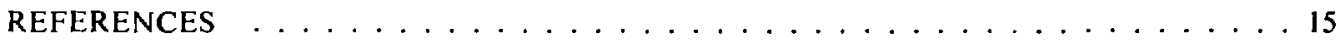

APPENDIX. WELL-LOGGING DATA LISTING $\ldots \ldots \ldots \ldots \ldots$ 


\title{
PLUTONIUM WELL LOGGING WITH THE PHOTONEUTRON URANIUM EXPLORATION SYSTEM
}

\author{
by
}

\author{
Michael P. Baker and Thomas Marks
}

\begin{abstract}
The Los Alamos National Laboratory prototype photoneutron uranium exploration system was recently demonstrated at the Hanford site near Richland, Washington, for Rockwell-Hanford Operations (Rockwell). The demonstration determined the field performance capabilities of the uranium exploration system for in situ, downhole measurements of transuranic waste concentrations. The uranium exploration system is indeed capable of detecting plutonium in the test wells at the waste sites investigated. The excellent signal-to-background ratio (15:1 in the worst case) of the system made positive plutonium determinations possible despite neutron bgackgrounds caused by spontaneous fission and $(\alpha, n)$ emitters. We present all the data collected from seven test wells and guidance for interpreting the data relative to the known uranium ore calibration of the system. The demonstration indicated no operational difficulties in the waste site environment, and routine use by Rockwell personnel appears practical.
\end{abstract}

\section{INTRODUCTION}

The Los Alamos National Laboratory prototype photoneutron uranium exploration system was demonstrated recently at the transuranic (TRU) waste sites on the Department of Energy's (DOE) Hanford Reservation near Richland, Washington. Rockwell-Hanford Operations (Rockwell), current operators of the site. contracted with the Jaboratory to determine the field performance capabilities of the uranium exploration system for in situ, downhole measurement of TRU wastes. The photoneutron system was developed under the sponsorship of the DOE as part of the National Uranium Resource Evaluation (NURE) Project.

The demonstration provided data for Rockwell to compare with other experimental studies conducted at the waste sites employing alternative analytical methods. This evaluation will form the basis for a feasibility study to determine which methods will be recommended for further research and development. The ultimate goal is to develop systems capable of subsurface plutonium assays at the federal $10 \mathrm{nCi} / \mathrm{g}$ fiducial.' Such systems. having sensitivity consistent with acceptable limits, would allow estimating plutonium inventory and monitoring possible plutonium migration toward ground water or toward the surface over long periods of time.

Los Alamos made no attempt to optimize the photo, neutron system for plutonium assay. We operated the system in its typical uranium exploration well-logging mode. Five test wells were logged in waste sites that had received plutonium-bearing process waste solutions, one in a uranium waste area. and one in a plutoniumcontaminated sludge tank.

We attempted to $\log$ the $4 \pi$ plutonium calibration facility at Hanford, but the probe length $(2.3 \mathrm{~m})$ and the lack of a run-out tube made data interpretation impossible. Thus, the data for the logged wells are presented as counts per second. We provide some 
guidance, however, by comparing the results to previous uranium calibration data.

\section{PROBE THEORY AND DESCRIPTION}

\section{A. Theory}

As currently constituted. the photoneutron uranium exploration system uses high-energy gamma rays from an $\sim 10-\mathrm{Ci}^{124} \mathrm{Sb}$ source to produce low-energy neutrons by the $(\gamma, n)$ reaction in a beryllium assembly (Fig. 1). These low-energy neutrons diffuse into the formation being logged and produce fissions in the uranium or plutonium present. Only the odd-mass nuclei undergo fission because the interrogating photoneutrons are lower in energy than the fission threshold of the even-mass nuclei. The fission of an odd-mass nucleus results. on the average, in the prompt emission of 2 or $3 \mathrm{n}$ with an average energy of $2 \mathrm{MeV}$.

Some of these emitted high-energy fission neutrons return to the borehole probe, where they are counted by an 18-atm helium recoil proportional counter biased to prevent counting the lower energy source neutrons. Thus, the system is operative $100 \%$ of the time, and neither source pulsing nor modulation is required.

Figure 2 illustrates pulse-height spectra obtained from the helium detector. The net integral counting rate above the pulse-height threshold is proportional to the number of fast neutrons returning to the borehole detector. For the Hanford waste site logging, there are three sources of counts above threshold. The first and most important source is the neutrons emitted from the induced fissions in the odd-mass plutonium isotopes. Second, the neutrons emitted passively from plutonium and other TRU compounds as a result of spontaneous fissions and $(a, n)$ reactions will produce a small signal. In the test wells logged, the passive signal ranged from $\sim 1$ to $7 \%$ of the induced signal. As illustrated in Sec. II.B, this passive signal can be measured by withdrawing the gamma-ray source from the beryllium assembly and logging the well with no photoneutron production. The third source of counts is a very small intrinsic background produced by the photoneutron source itself when no fissile materials are present.

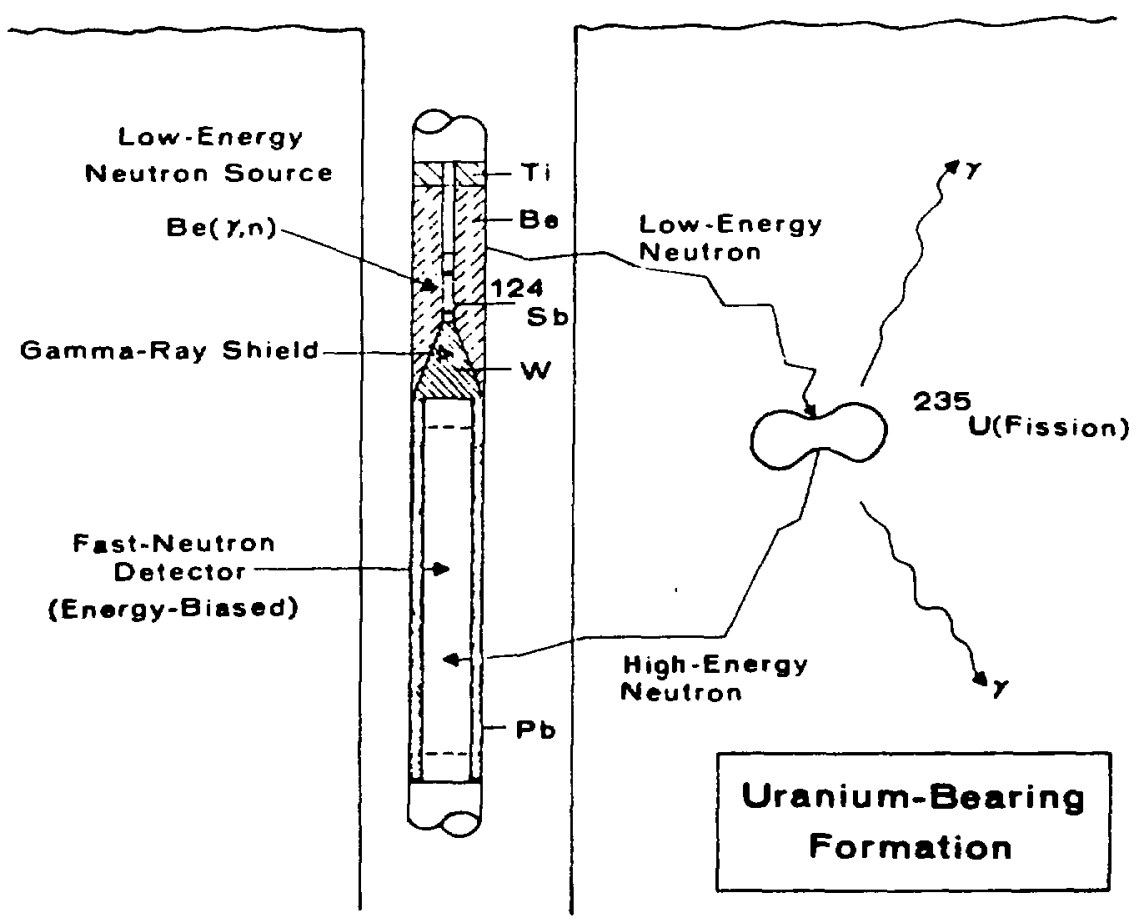

Fig. 1. Schematic of the principle of the photoneutron uranium exploration system. 


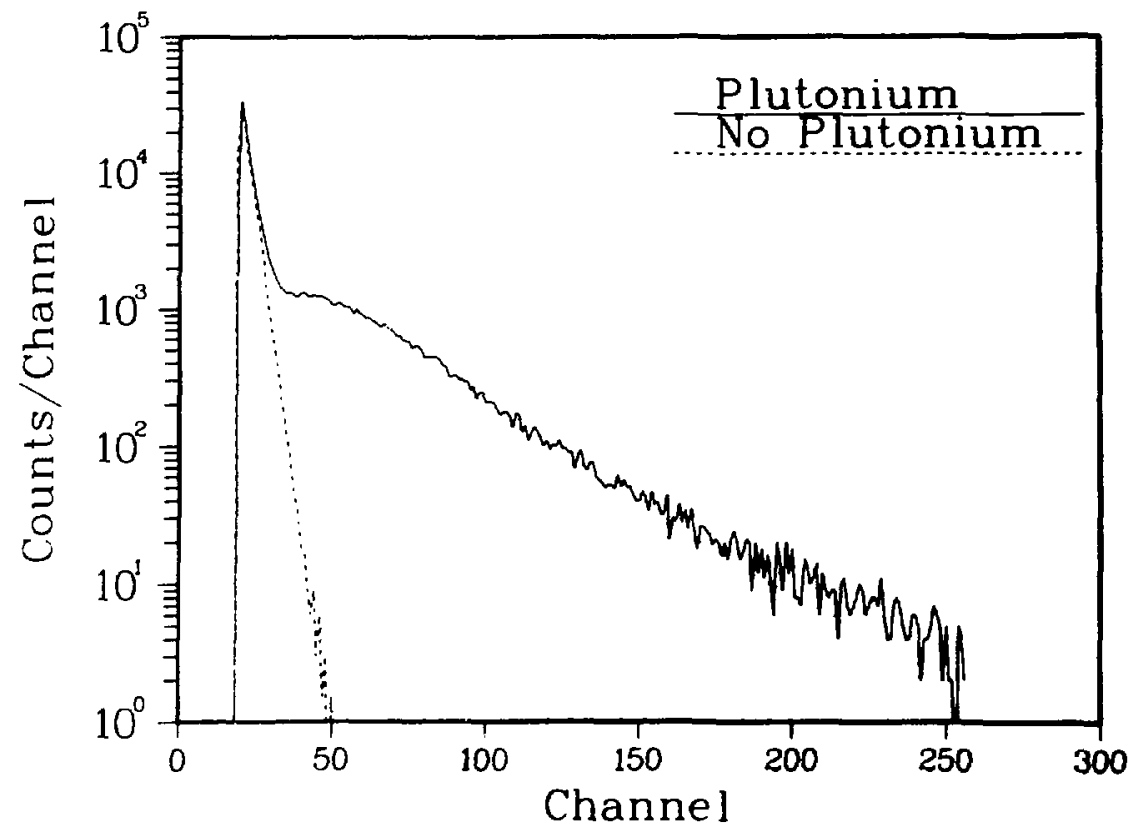

Fig. 2. Pulse-height spectra from the 18 -atm ${ }^{4} \mathrm{He}$ recoil proportional counter with and without plutonium in the formation logged.

\section{B. Method of Operation}

Figure 3 illustrates the probe as it appears in field use. The lower section of the probe, containing the highenergy gamma-ray source. is stored in a depleted uranium cask that serves as a biological shield during transportation to the logging site. At the logging site, a support plate is placed over the borehole and leveled. Modifications were made to the support plate for the Hanford demonstration to allow its use on wells where the casing extends several feet above ground level. The shield is lowered onto the plate and held securely with guide pins. The logging winch lowers the upper portion of the probe, which contains the beryllium assembly, the helium detector, and the downhole electronics, onto the lower portion containing the radioactive source. The assembled probe is then lowered through the shield and into the borehole.

Figure 4 gives a more detailed view of the shield mechanical design. The lower portion of the probe with the gamma-ray source is contained in the shipping/storage shield, except during logging operations. The upper portion of the probe is stored on the logging truck. In preparation for a logging operation, the two pieces are coupled by a threaded collar located on the lower section near the top of the shield. A trap door near the bottom of the shield is actuated, allowing the assembled probe containing the gamma-ray source to be lowered into the borehole.

Initially. the gamma-ray source is retained in a cylindrical tungsten shield inside the lower portion of the probe. After the probe is lowered a short distance into the borehole, a remotely controlled motor coupled to a lead screw contained in the probe drives the gamma-ray source up into the beryllium sleeve, and the production of photoneutrons begins. With this method, neutronshielding materials need not be incorporated in the cask because negligible neutron production occurs while the probe is above ground. The ground and the borehole tluid serve as biological shielding against the neutron and gamma radiation emanating from the probe during the logging operation in the borehole. For wells where the casing extends above ground level, lead bricks are stacked around the casing to provide radiation protection while the probe is lowered from and raised into the shield.

After the borehole is Iogged. the motor drives the gamma-ray source back into the tungsten cylinder, and the probe is raised back into the shield. Then the upper portion of the probe is uncoupled and removed while the 


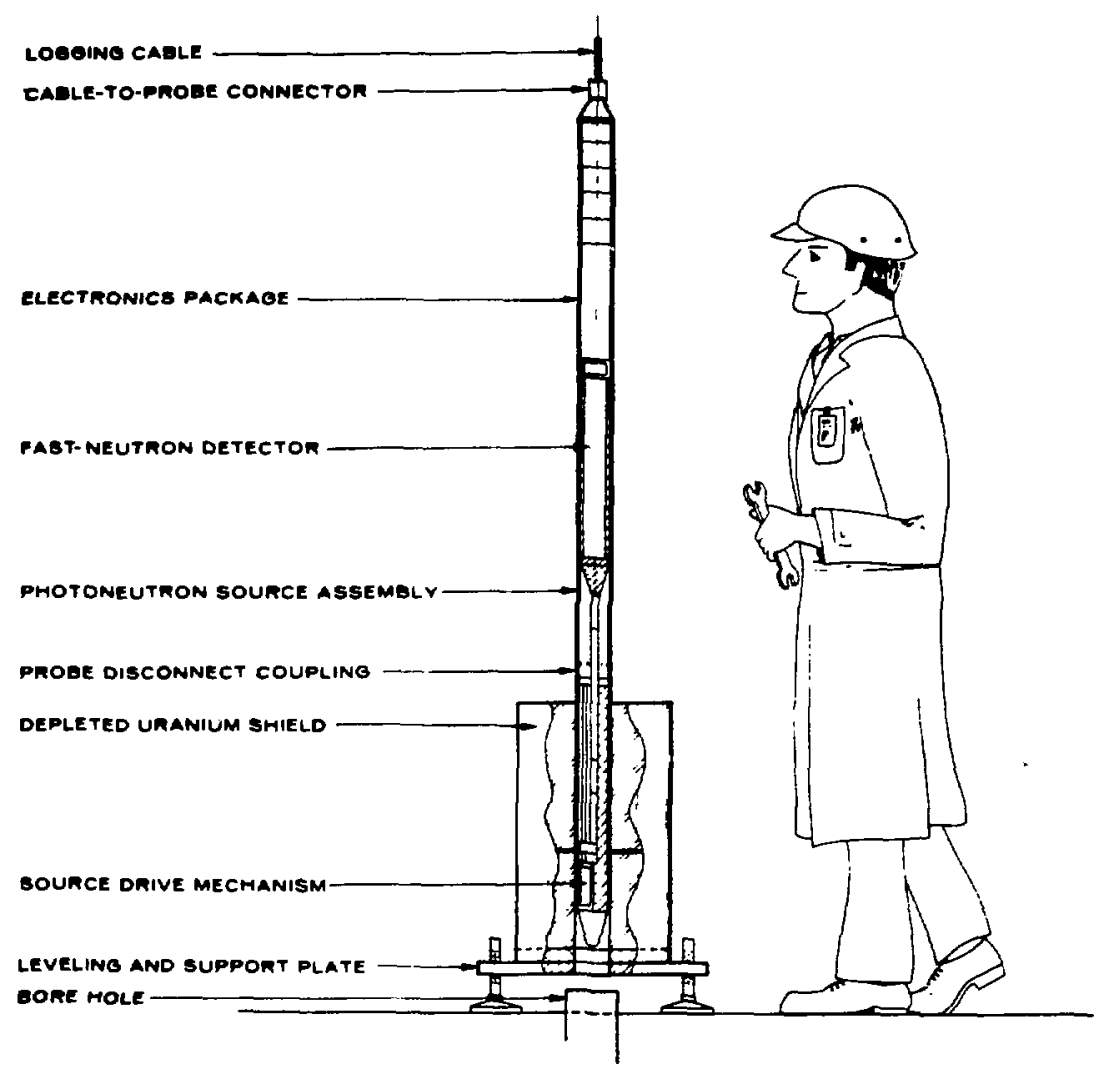

Fig. 3. Diagram of the photoneutron uranium exploration system in field use.

lower part remains in the shield. A shielding cap is bolted to the top of the cask during transportation. A tungsten plug that fills the source passageway and prevents radiation streaming is an integral component of the cap. The tungsten bull nose at the extreme lower end of the probe limits the escape of radiation from the bottom of the cask. (For a more detailed description of the mechanical and electrical design of the photoneutron uranium exploration system, see Baker and Marks. ${ }^{2}$ )

All wells logged at Hanford, except those at the calibration facility, were in exclusion areas. Because of potential radiological contamination, participating personnel always wore protective clothing. Radiation-mónitoring (RM) personnel, paying particular attention to the logging cable and probe, found no evidence of contamination at any time during the demonstration.

\section{LOG INTERPRETATION}

\section{A. Uranium Log Interpretation}

Before logging the wells at the Hanford waste site, we calibrated the photoneutron probe at the DOE uranium calibration facility in Grants, New Mexico. This was achieved by logging a series of concrete models containing known uranium concentrations. Chemical analyses of concrete samples, obtained when the models were constructed, indicated that the uranium is distributed homogenously throughout the concrete matrix material. The model dimensions are such that the uranium zones appear infinite to the probe. The calibration was de-

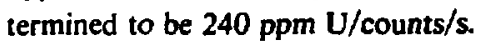

The interpretation of a log obtained in a well for which the surrounding formation parameters are unknown 


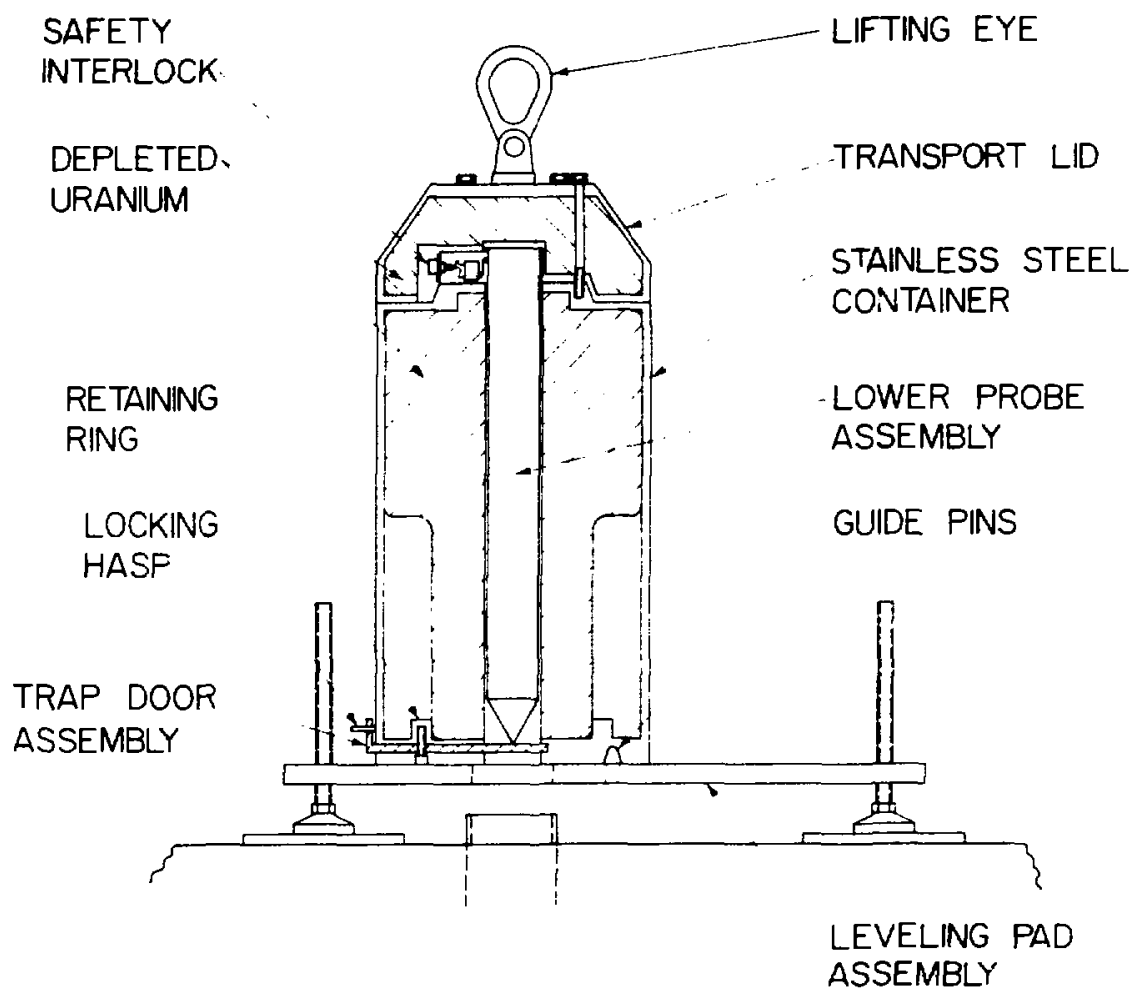

Fig. 4. Detailed view of source shield and lou'er section of the photoneutron logging probe.

must take into account borehole diameter and fluid, wellcasing material and thickness, and formation density and porosity. In principle. a change in any of these parameters relative to the conditions at the calibration facility requires that a correction factor be applied to the calibration factor relating the fast-neutron detector counting rate to uranium ore grade.

The dependences of probe response on these parameters have been studied in detail on a more elaborate set of models at the Grand Junction DOE calibration facility. Because the study results have been published. ${ }^{2}$ only a brief description of the dependences relevant to the Hanford waste site are discussed here.

For air-filled holes, the response of the photoneutron probe is constant for diameters $<23 \mathrm{~cm}$. Because the Hanford wells and the calibration facility models have hole diameters within this range, no correction is re quired. Although measurements have shown that polyvinyl chloride (PVC) well casing reduces the photoneutron probe response. calculations indicate that the steel pipes used to case the wells at Hanford have only a minor effect on the response. Similarly, because the photoneutren probe has a small distance berween so.2r.: and detector. the measured formation perosity d: pendence is slight. in the range of $7-1411.0 \%$ water Although we have not calculated the dependence of th: probe response on moisture content over a litg: tange we do not expect the effect to be large.

The only significant borehole parameter correction then for the dry wells at the Hanford site is that for formation density. This dependence has not been measured or calculated directly, but we believe the -response of the photoneutron probe (counts/second/parts per million plutonium) is direct's proportional to the bulk density of the formation. This correction can be made simply by comparing the bulh density of the Hanford waste site to that of the calibr: tion models.

\section{B. Relative Plutonium-Uranium Response}

The photoneutron logging system was calibrated a! is uranium facility before its use at the Hanford waste sites. 
Although a proper weapons-grade plutonium calibration was not obtained, an approximate relationship between uranium and plutonium responses can be derived for the case of homogeneous fissile-material distributions. Because the federal burial fiducial " is given in terms of alpha activity per unit mass $(10 \mathrm{nCi} / \mathrm{g})$, a conversion to weight percentage (parts per million) is needed. The first step in this procedure is to determine the normalized decay rate of typical weapons-grade plutonium. In Table I. the result of $\sim 78 \mathrm{mCi} / \mathrm{g}$ is obtained from the isotopic fractions. half-lives, and atomic weights of the relevant isotopes. This quantity can be combined with the federal waste burial fiducial of $10 \mathrm{nCi} / \mathrm{g}$ to find the weight percentage equivalent of weapons-grade plutonium metal.

$\frac{10 \mathrm{nCi} / \mathrm{g}}{78 \mathrm{mCi} / \mathrm{g}}=1.3 \times 10^{-7}=130$ parts per billion

$$
=1.3 \times 10^{-5} w t \%
$$

This result can be related to the calibrated response to uranium ore by correcting for fissile isotope fraction, fission cross section. fission neutron multiplicity, and formation density. Applying all of these factors, we find that a distribut:on of $10 \mathrm{nCi} / \mathrm{g}$ of weapons-grade plutonium in the Hanford formations is equivalent to a concentration of $\sim 20 \mathrm{ppm}(0.002 \mathrm{wt} \%)$ natural uranium in the DOE calibration models. The largest uncertainty in relating uranium and plutonium responses is in the fission cross section. Here we used the thermal neutron cross-section values to make the conversion. In the relatively dry Hanford formations, a significant fraction of the observed signal probably results from fissions induced by epithermal neutrons. Plutonium-239 has a larger average fission cross section in the epitnermal energy domain than does ${ }^{235} \mathrm{U}$. In the absence of appropriate calibration models. this correction can be quantified only by transport calculations. Such calculations have not been performed, and th: effect has been ignored in the conversion discussed above. (We expect the correction to be $-50 \%$ or less.)

\section{Data Interpretation}

The preceding analysis and uranium calibration can be used to approximately convert the well-logging data presented later in the report from counts per second to the average plutonium concentrations in nanocuries per gram. The reader must exercise caution in interpreting the results. as the calibration is correct only for fissile material distributed homogeneousiy thoughout a volume in a subsurface formation equal to or greater than the $\sim 60-\ell$ volume of photoneutron probe sensitivity. If the distribution of fissile material is inhomogeneous. then small amounts of material at short distances from the borehole can give responses equivalent to larger amounts of material at greater distances.

In addition. the reader must use care in comparing these results with those obtained by other methods. For

TABLE 1. Decay Rates of the Plutoniy i Isotopes.

\begin{tabular}{|c|c|c|c|c|}
\hline Isotope & $\begin{array}{l}T_{1 / 2} \\
(y r) \\
\end{array}$ & $\begin{array}{l}\text { Isotopic } \\
\text { Decay Rat } \\
(\mathrm{Ci} / \mathrm{g})\end{array}$ & $\begin{array}{c}\text { sotopic } \\
\text { Fraction }^{2}\end{array}$ & $\begin{array}{l}\text { Normalized Alpha } \\
\text { Decay Rate } \\
(\mathrm{Ci} / \mathrm{g})\end{array}$ \\
\hline${ }^{239} \mathrm{Pu}$ & $2.41 \times 10^{4}$ & $6.22 \times 10^{-2}$ & 0.939 & $5.84 \times 10^{-2}$ \\
\hline${ }^{240} \mathrm{Pu}$ & $6.54 \times 10^{3}$ & $2.28 \times 10^{-1}$ & $5.74 \times 10^{-2}$ & $1.31 \times 10^{-2}$ \\
\hline${ }^{241} \mathrm{Pu}$ & 14.7 & $1.01 \times 10^{2}$ & $1.92 \times 10^{-3}$ & -..- \\
\hline${ }^{242} \mathrm{Pu}$ & $3.76 \times 10^{5}$ & $3.93 \times 10^{-3}$ & $2.05 \times 10^{-4}$ & $8.06 \times 10^{-7}$ \\
\hline${ }^{238} \mathbf{P u}$ & 87.7 & $1.72 \times 10^{1}$ & $1.41 \times 10^{-4}$ & $2.43 \times 10^{-3}$ \\
\hline \multirow[t]{2}{*}{${ }^{241} \mathrm{Am}$} & 432 & 3.44 & $1.15 \times 10^{-3}$ & $3.94 \times 10^{-3}$ \\
\hline & & & Total & $7.79 \times 10^{-2}$ \\
\hline
\end{tabular}

${ }^{2} \mathrm{For}{ }^{241} \mathrm{Pu}$ and ${ }^{241} \mathrm{Am}$, we assume plutonium separation occurred $\sim 10 \mathrm{yr}$ ago.

bPlutonium-241 is primarily a beta emitter and thus is not included in the normalized alpha decay rate. For long-term burial, one could consider all of the ${ }^{24} 1 \mathrm{Pu}$ to have decayed to ${ }^{241}$ Am. This assumption has only a minimal effect on the nornialized alpha decay rate. 
example, a vertical profile of a thin. horizonta! zone of fissile material will appear to have finite vertical extent because of the spatial resolution of the probe used to perform the measurement. Generally, the greater the volume of sensitivity. the larger the spatial resolution and vice versa. The photoneutron probe has a relativelv small volume of interrogation and therefore good spatial resolution. A thin fissile zone appears as a Gaussianshaped vertical profile with FWHM of $\sim 27 \mathrm{~cm}$ to the photoneutron probe.

\section{HANFORD LOGS}

Plots of the data from the Hanford waste site are presented below: actual numerical results are tabulated in the Appendix. Five wells were logged in two plutonium liquid waste disposal sites (the 216-Z-1 A and 216-Z-12 cribs). one in a uranium waste area. and one in a plutonium-contaminated waste sludge tank (241-Z-361).

\section{A. 2I6-Z-1A Crib}

The 216-Z-1A crib received aqueous waste from the Plutonium Reclamation Facility located in the nearby $Z$ plant complex. The waste solution was primarily a concentrated $(\sim 6 \mathrm{M})$ sodium nitrate solution with a $\mathrm{pH}$ of $\sim 1$. A previous field study characterized the distribution of plutonium and americium in the sediments beneath the crib. ${ }^{3}$ Wells $299-W 18-149,-159,-170$, and -175. which had been drilled in the crib to obtain sediment samples for laboratory analysis, were used to provide access for the sonde.

All wells were cased with $15-\mathrm{cm}$-i.d. steel pipe and w'ere about $35 \mathrm{~m}$ deep. Generally. an active (photoneutron source activated) dynamic scan was logged at $0.3 \mathrm{~m} / \mathrm{min}$ in the shallow parts of the weils. where the higher plutonium concentrations were found. The active scan was usually followed by a passive (photoneutron source deactivated) dynamic scan at the same logging speed and depths. Because delayed neutrons represent $<1 \%$ of the total neutrons emitted in fission, we encountered no difficulties with activation of the material surrounding the well. In some cases, active dynamic scans in the deeper parts of the wells, where the plutonium concentrations are generally lower, were logged at $1.5 \mathrm{~m} / \mathrm{min}$. Data were usually recorded in $15-\mathrm{s}$ intervals.
1. Well 159. Figures 5 and 6 show results from Well 159. Figure 5 illustrates counting rates from active and passive scans logged at $0.3 \mathrm{~m} / \mathrm{min}$ for depths from 1 to $16 \mathrm{~m}$. The counting-rate scale is logarithmic and. at a depth of about $3 \mathrm{~m}$. indicates a strong peak, the strongest signal observed in any measurements obtained at Hanford. A second peak. not fully resolved from the first, occurs at a depth of $\sim 4 \mathrm{~m}$. A third peak of much lower magnitude occurs at $13 \mathrm{~m}$. We observed plateaus at a variety of counting rates at other depths throughout the scan.

The passive scair (Fig. 5) yielded statistically meaningful results only in the regions near the major peaks where the signal is about one-fiftieth of that obtained in the active scan. The maximum signal in the passive scan occurs at a somewhat greater depth than it does for the active scan. The depth shift is due to the differing geometrical sensitivities for the active and passive modes. For the passive mode. the axial point of maximum sensitivity lies at the center of the fast-neutron detector. In the active case. this point is situated midway between the center of the photoneutron source and the center of the fast-neutron detector. shiffing the depth at which the maximum counting rate is observed about $0.2 \mathrm{~m}$.

Figure 6 shov:s data obtained in Well 159 logged at $1.5 \mathrm{~m} / \mathrm{min}$ for depths from 1 to $36 \mathrm{~m}$. These data indicate much-reduced concentrations of plutonium around this well at depths exceeding $14 \mathrm{~m}$. Nearer the surface the data reproduce the data of Fig. 5 very well. Note. however. that the poorer depth resolution at the higher logging speed results in peaks that are somewhat broader and lower in magnitude.

2. Well 175. Figures $7-9$ show data obtained in Well 175. The $0.3-\mathrm{m} / \mathrm{min}$ scans in Fig. 7 illustrate peak plutonium concentrations at depths of $\sim 3$ and $5 \mathrm{~m}$. The peaks are lower in magnitude but considerably broader than those observed in W'ell 159. Active-to-passive ratios rạnge from 75 to 100 for this zone. The $1.5-\mathrm{m} / \mathrm{min}$ active scan in Fig. 8 demonstrates the relatively low plutonium concentrations found at depths below about $18 \mathrm{~m}$.

Figure 9 illustrates additional $0.3-\mathrm{m} / \mathrm{min}$ active scans obtained in Well 175 . In the first of these. the entire well $(1-35 \mathrm{~m})$ was scanned with the probe in the nominal sidewalled position in the well. Note again the weaker peak at a depth of about $15-16 \mathrm{~m}$. Careful comparison of this scan with that of Fig. 7 indicates very good reproducibility of measurement. In the second set of measurements, the probe was centered in the well and the 


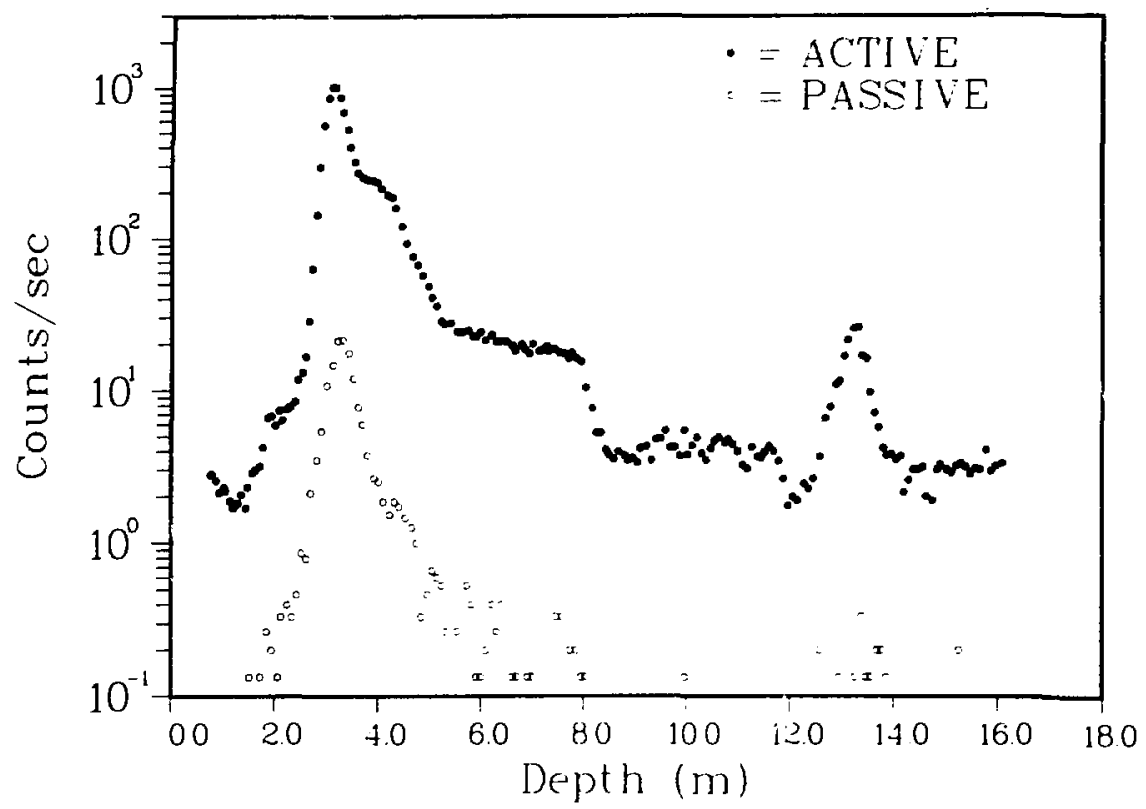

Fig. 5. Active and passive scans of Well 159 logged at $0.3 \mathrm{~m} / \mathrm{min}$ for depths from 1 to $16 \mathrm{~m}$.

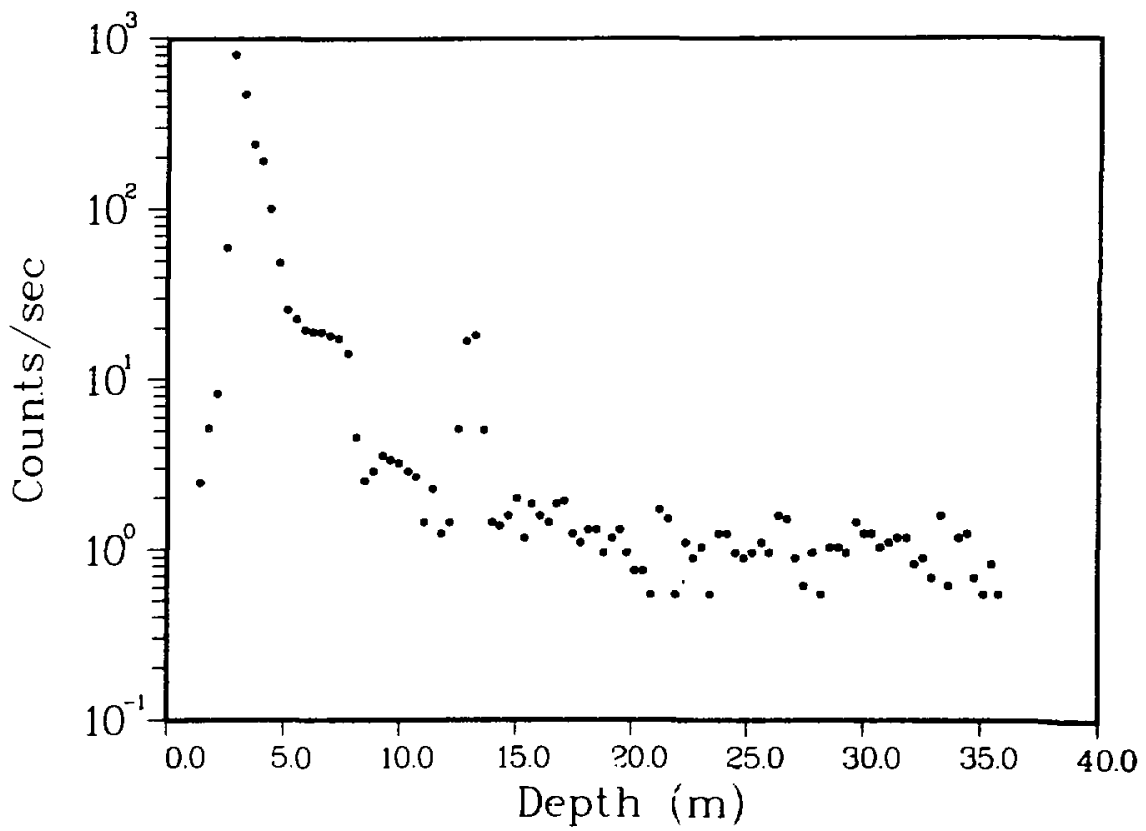

Fig. 6. Active scan of Well 159 logged at $1.5 \mathrm{~m} / \mathrm{min}$ for depths from 1 to $36 \mathrm{~m}$. 


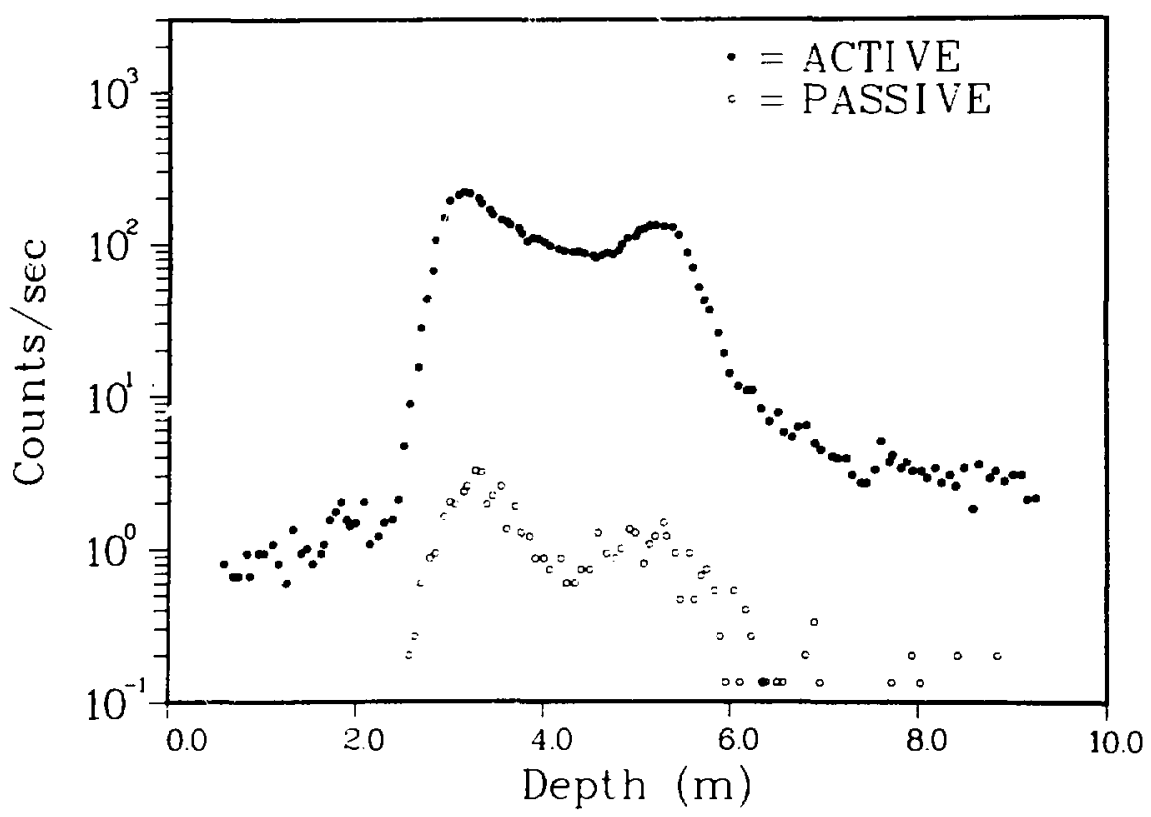

Fig. 7. Active and passive scans of Well 175 logged at $0.3 \mathrm{~m} / \mathrm{min}$ for depths from 1 to $9 \mathrm{~m}$.

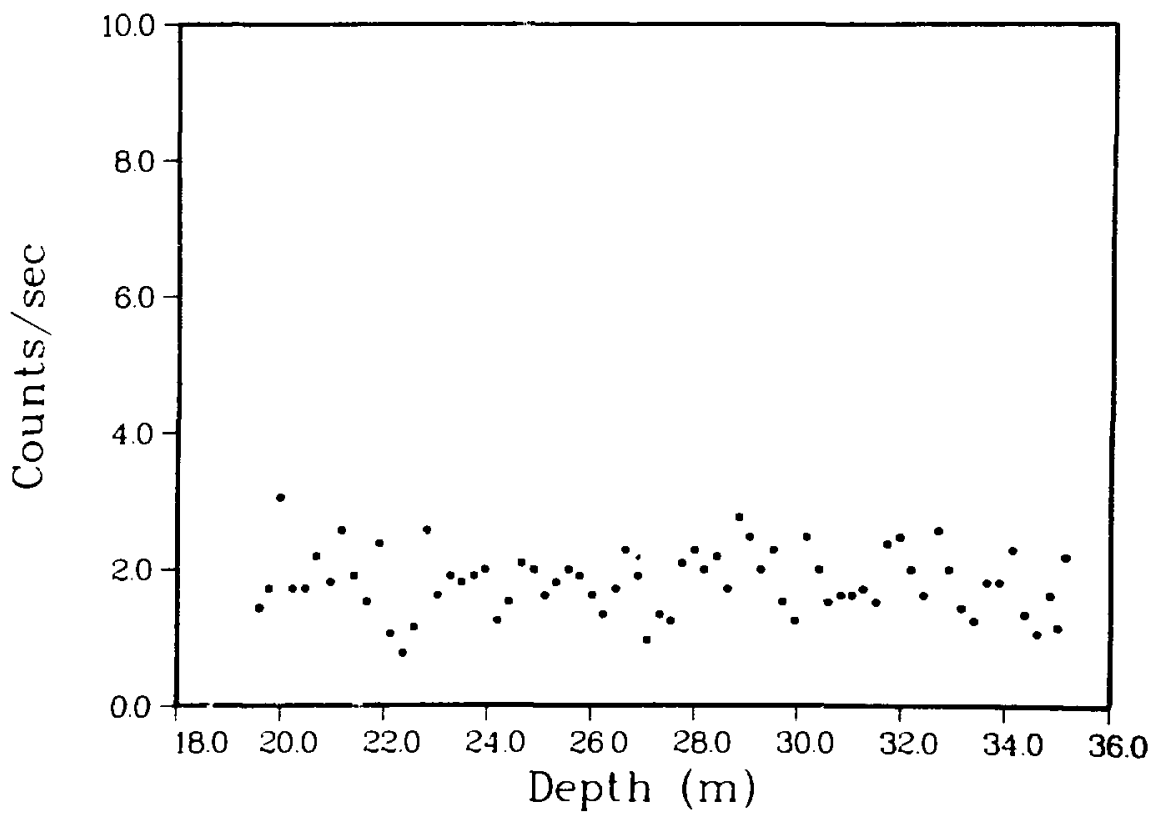

Fig. 8. Active scan of Well 175 logged at $1.5 \mathrm{~m} / \mathrm{min}$ for depths from 19 to $35 \mathrm{~m}$. 


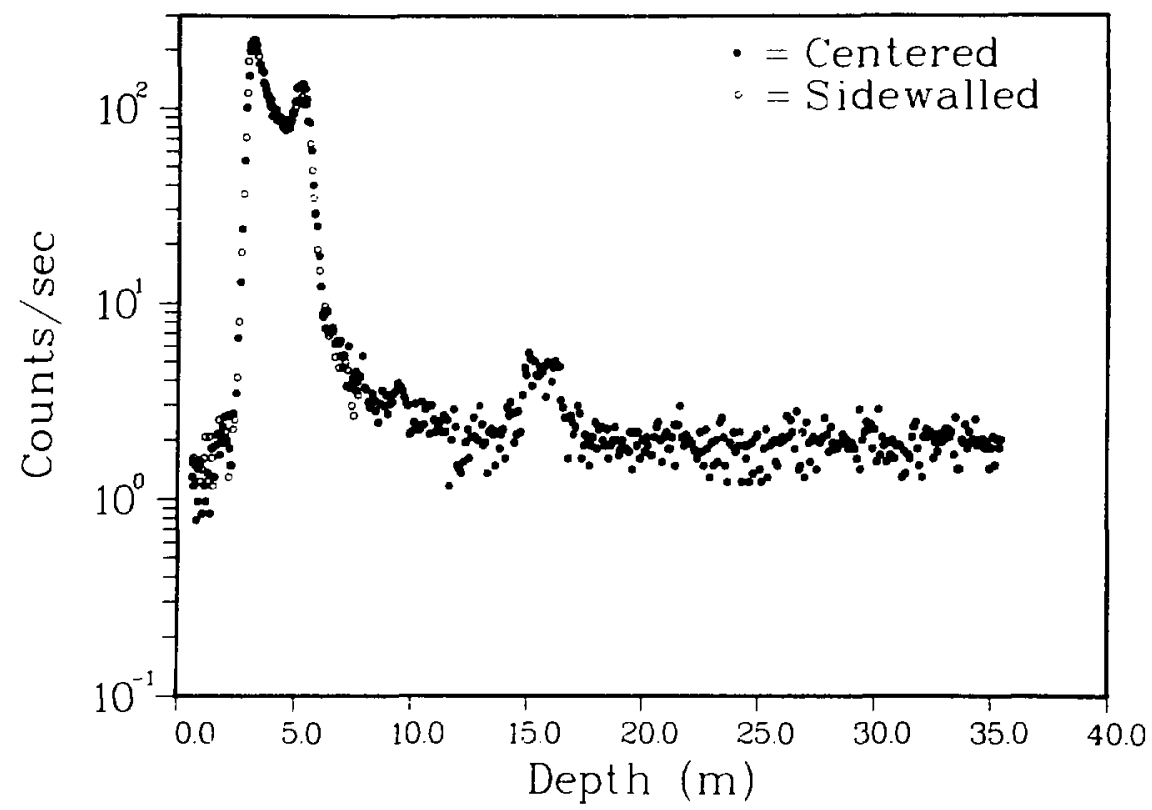

Fig. 9. Additional $0.3 \mathrm{~m} / \mathrm{min}$ actiyc scans of Well 175 for depths from 1 to $36 \mathrm{~m}$ with the probe side-walled in the well and from 1 to $7 \mathrm{~m}$ with the probe centered.

scan of the region from 1 to $7 \mathrm{~m}$ was repeated. The agreement between these two scans indicates that the radial position of the probe in the well does not significantly influence the results.

3. Wells 170 and 149. Figures 10 and 11 show the $0.3-\mathrm{m} / \mathrm{min}$ dynamic scans of Wells 170 and 149 , respectively. Data were obtained only for the relatively higher plutonium concentrations at the shallower depths. Although Well 170 is located just $2 \mathrm{~m}$ from Well 175 , the profiles are markedly different. The major peak remains at a depth of $3 \mathrm{~m}$. but the secondary peak at $\sim 5 \mathrm{~m}$ is somewhat smaller and sinears to lower depths. The Well 149 scans (Fig. 11) are similar to the Well 170 scans, but a small satellite peak at $\sim 2 \mathrm{~m}$ is more evident. The active-to-passive ratios are approximately $50: 1$.

\section{B. Storage Tank Well (214-Z-361)}

Dynamic active and passive scans (Fig. 12) also were obtained with the photoneutron probe in a storage tank containing plutonium-contaminated liquids and sludge. The tank is 4 by 8 by $\sim 5 \mathrm{~m}$ deep and is filled to about $2.5 \mathrm{~m}$. The $\operatorname{logs}$ were run at $0.2 \mathrm{~m} / \mathrm{min}$ in an $11.4-\mathrm{cm}$ - diam aluminum pipe that penetrated the center of the tank.

At $\sim 4 \mathrm{~m}$ or mort the probe is below the surface of the liquid sludge. and a large ratio $(\sim 20)$ of active-to-passive signals is observed. As the probe moves upward in the borehole. it breaks the air-liquid interface and the active signal decreases dramatically (at $\sim 4 \mathrm{~m}$ ). The passive signal. on the other hand, declines much more slowly with decreasing depth. a phenomenon not observed in the disposal cribs.

Interpretation of the observed data requires careful consideration of the air volume above the plutoniumbearing medium. The net active signal diminishes rapidly with distance above the interface as a result of solidangle effects. The passive signal decreases more slowly because the fast-neutron detector views a large-ared neutron source without any intervening absorbers. Because the detector is shielded by the adjacent nonplutonium-bearing material, it does not observe the large passive signal in the subsurface earth formations as the probe passes out $c$ a a plutonium-bearing zone.

Using the calibration for nomogeneous uranium ore discussed in Sec. IIl and the bulk density of the material in the tank $\left(1.31 \mathrm{~g} / \mathrm{cm}^{3}\right)$, we derived a plutonium concentration of $0.20 \mathrm{~g} / \ell$ for the peak counting rate 


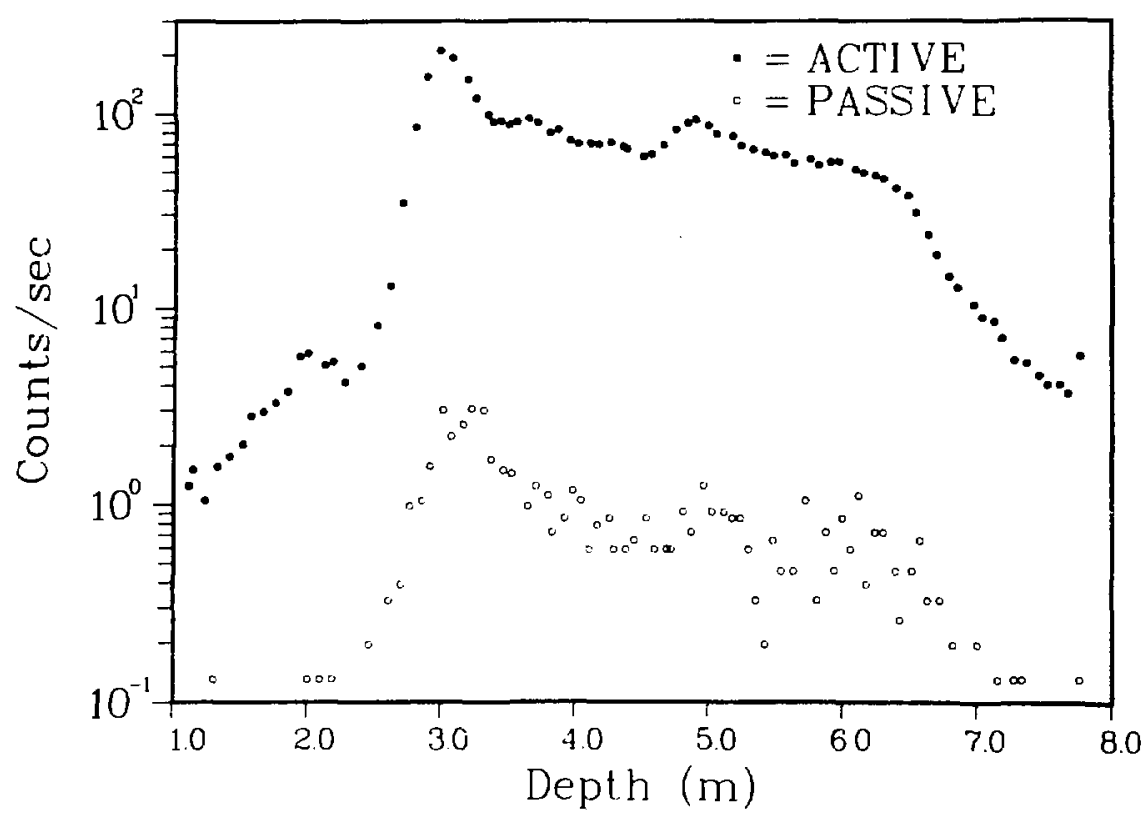

Fig. 10. Active and passive scans of Well 170 logged at $0.3 \mathrm{~m} / \mathrm{min}$ at depths of 1 to $8 \mathrm{~m}$.

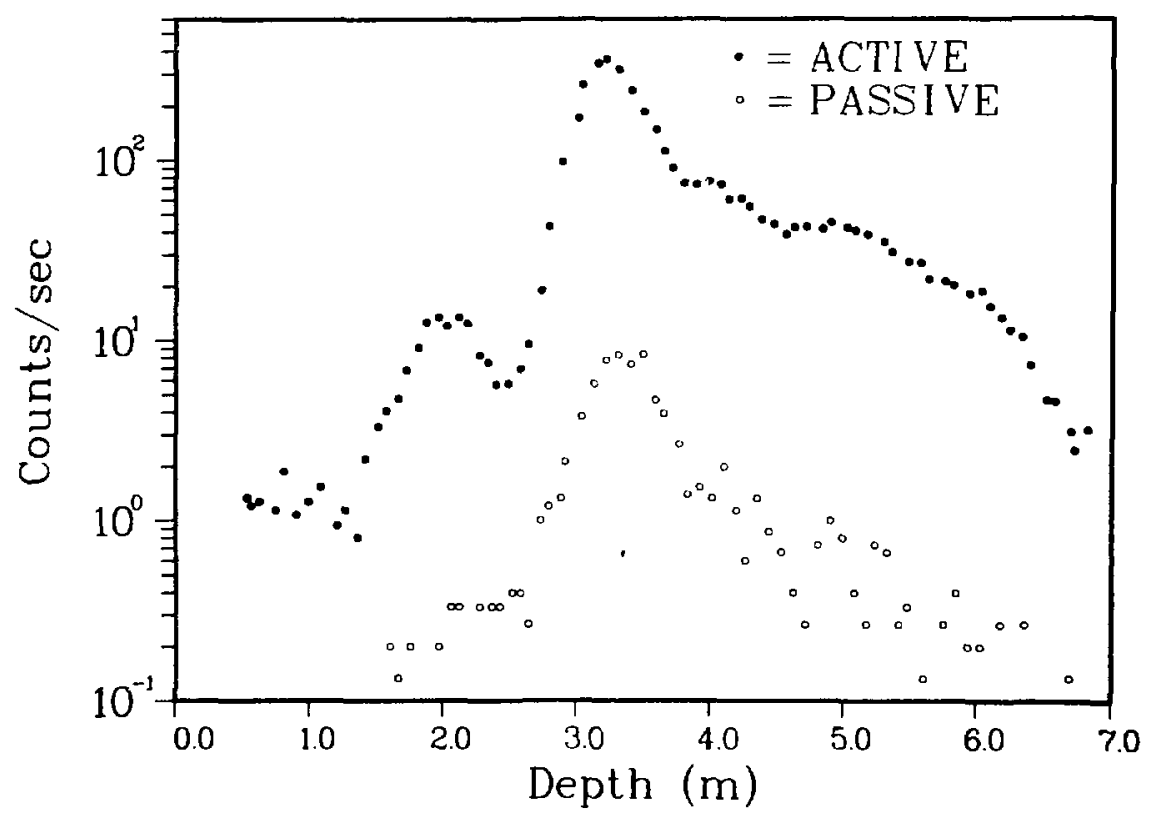

Fig. 11. Active and passive scans of Well $149 \operatorname{logged}$ at $0.3 \mathrm{~m} / \mathrm{min}$ at depths of 1 to $7 \mathrm{~m}$. 


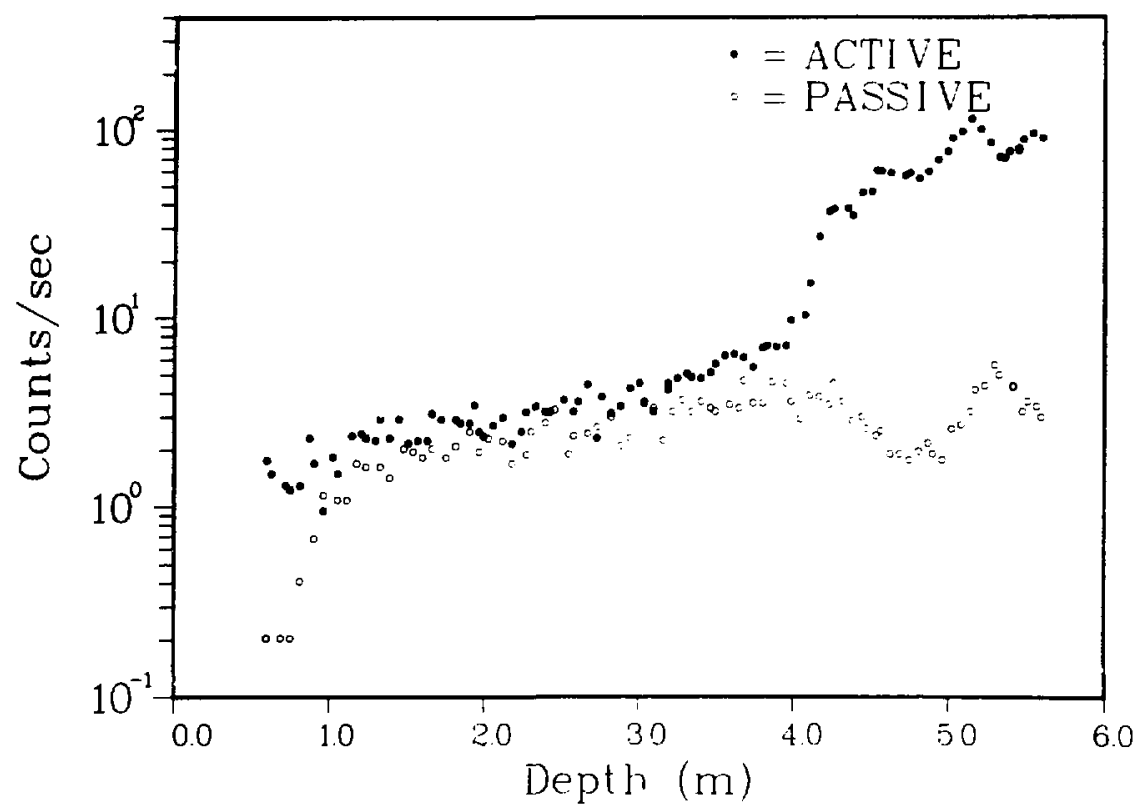

Fig. 12. Active and passive scans of Well 361 (storage tank well) loggud at $0.2 \mathrm{~m} / \mathrm{min}$.

$(\sim 100$ colints $/ \mathrm{s})$ at a depth of $5 \mathrm{~m}$. Agair, the reader must be extremely cautious interpreting this result. Althougn the homogeneity within the volume sampled might be superior to that in the subsurface formations. the derivation is not based on an appropriate calibration. As discussed earlier, changes in water content ranging from 7-14 wt \% are known to have little effect on the probe response. but the $70 \mathrm{wt} \%$ water content of the sludge lies well outside the domain of known behavior.

\section{Uranium Well (W-19-3)}

A well drilled through the outfall of a low-level uranium waste drain was also logged. The uranium in this waste stream had been depleted to $\sim 0.2 \%{ }^{235} \mathrm{U}$. The well extended $\sim 60 \mathrm{~m}$ and was cased with a $20-\mathrm{cm}$-i.d. steel pipe. The well was logged in the active mode from $57 \mathrm{~m}$ to the surface at $1.5 \mathrm{~m} / \mathrm{min}$. Data were dumped at 10-s intervals.

Figure 13 shows the data with the counting rate on a linear scale. Very little signal was detected and no structure was discernible. Note that the counting rate in the uranium well is lower than the lowest rates recorded in any of the plutonium wells.

\section{D. $216 \cdot Z-12$ Crib}

The 216-Z-12 crib received aqueous waste from laboratories and continuous process operations in the $Z$. plant complex. The waste was primarily a dilute $(\sim 0.1 \mathrm{M})$ sodium. fluoride, and nitrate solution with a $\mathrm{pH}$ of $\sim 8$. a significantly different composition from that discharged to the $216-\mathrm{Z}-1 \mathrm{~A}$ crib. Thus. we anticipated that the distribution of plutonium in the sediments beneath the two cribs would be different. The 216-Z-12 crib was the subject of a recent study to characterize the distribution of plutonium and americium in the sediments beneath the crib. ${ }^{4.5}$ Well 299-W18-181. drilled as part of the study. penetrated the crib bottom and provided access for the sonde.

Figures 14 and 15 show the dynamic active and passive scans obtained from this well. Active and passive data logged at $0.3 \mathrm{~m} / \mathrm{min}$ at depths up to $16 \mathrm{~m}$ (Fig. 14) show as a major feature a peak at a depth of $6 \mathrm{~m}$ with an active-to-passive ratio of 15:1. The presence of fluorine in the waste stream discharged to this crib probably is responsible for increased $(\alpha . n)$ yield and thus a lower active-to-passive ratio. Also, this ratio is similar to the ratio observed below the surface of the liquid sludge in tank 214-Z-36I. This result is reasonable because the 


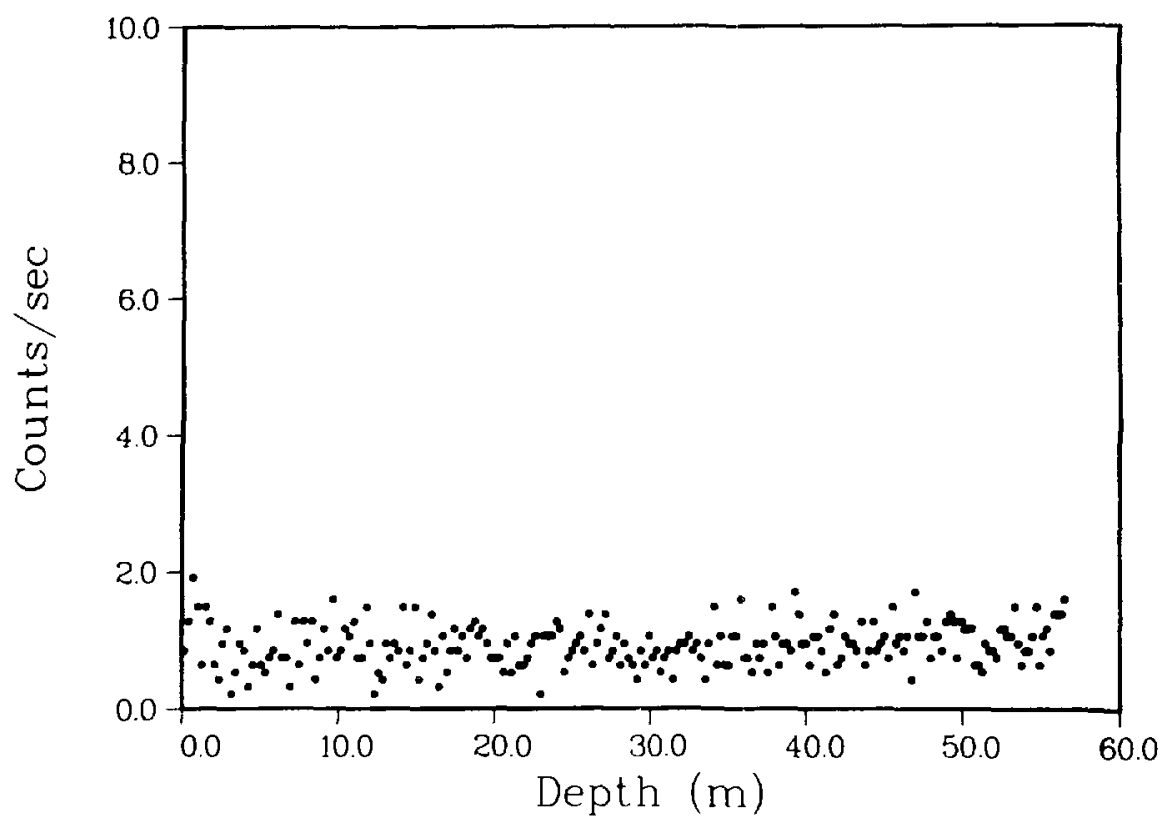

Fig. 13. Active scan of Well W-19-3 (uranium well) logged at $1.5 \mathrm{~m} / \mathrm{min}$ at depths from $57 \mathrm{~m}$ to the surface.

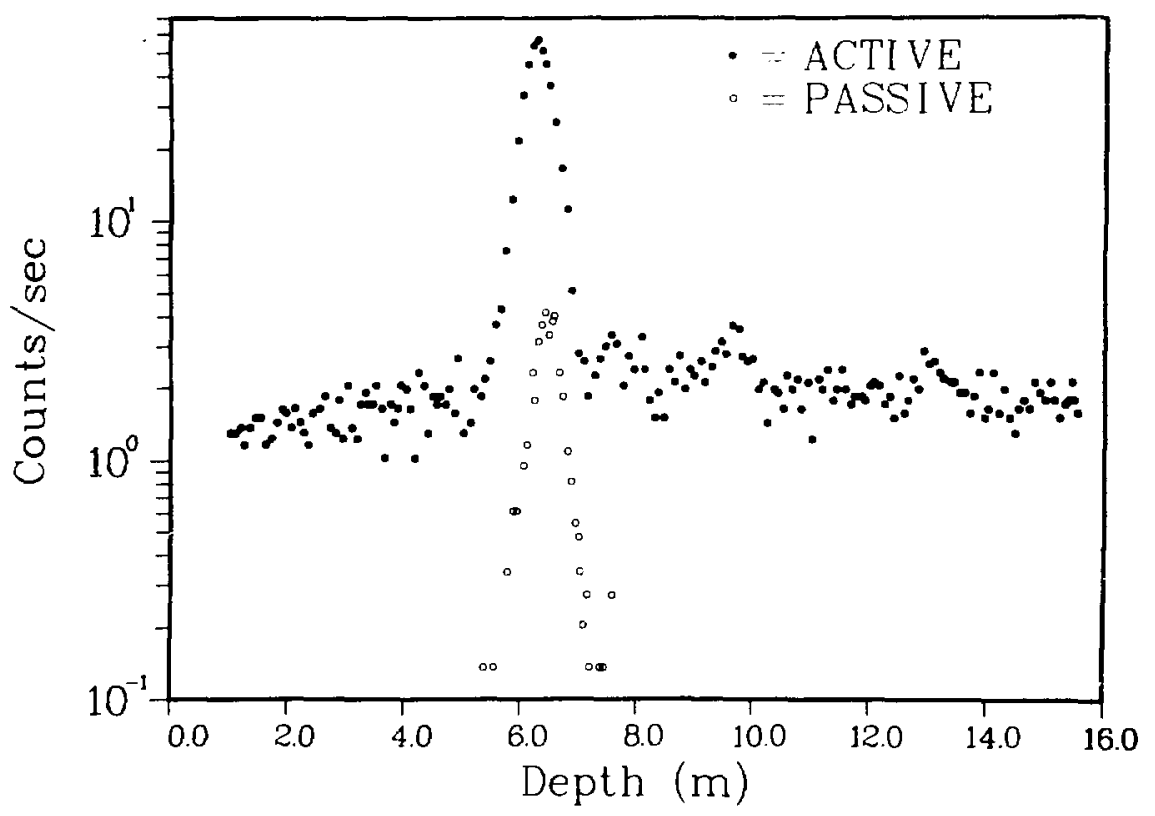

Fig. 14. Active and passive scans of Well 181 logged at $0.3 \mathrm{~m} / \mathrm{min}$ at depths of $\mathrm{I}$ to $15 \mathrm{~m}$. 


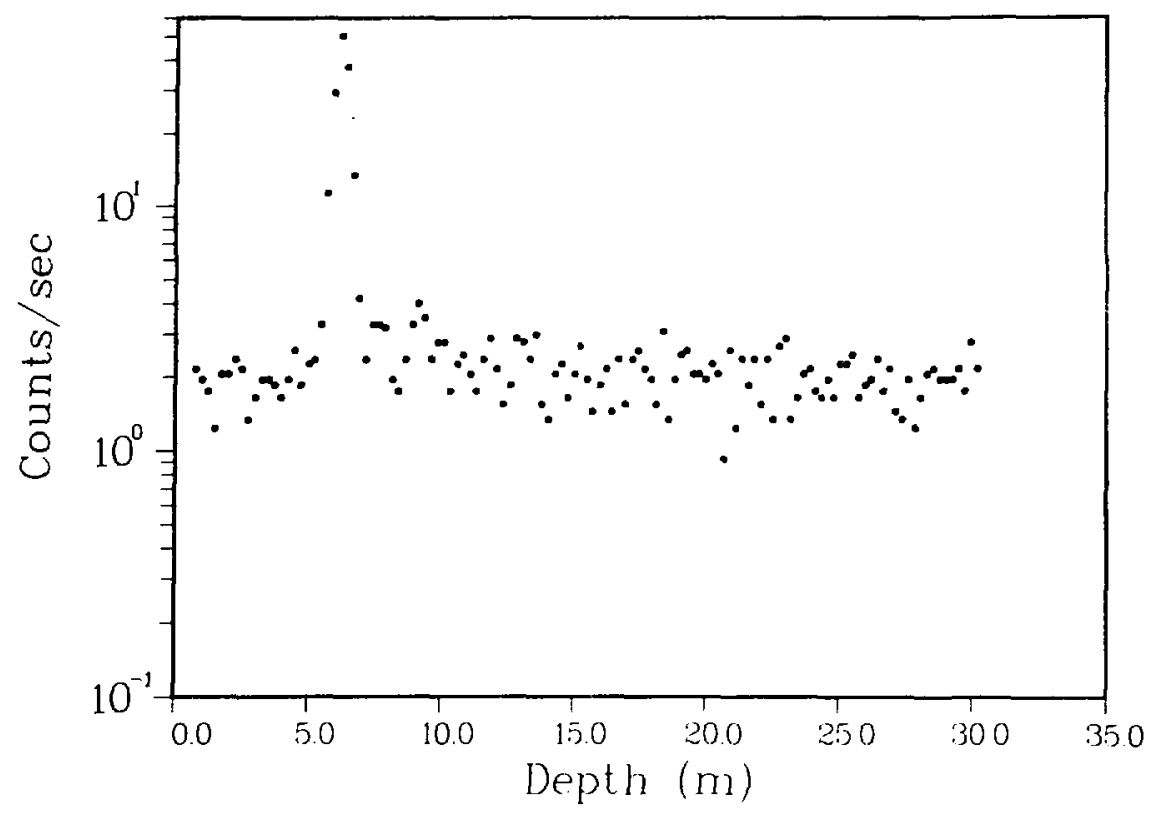

Fig. 15. Active scan of Well $181 \mathrm{logged}$ at $1.5 \mathrm{~m} / \mathrm{min}$ from a depth of $30 \mathrm{~m}$ to the surface.

tank was used to settle particulate material in the waste stream discharged to the $216-\mathrm{Z}-12$ crib. Figure 15 shows a repeated active scan logged at $1.5 \mathrm{~m} / \mathrm{min}$ from $30 \mathrm{~m}$ to the surface. No additional structure is evident.

\section{CONCLUSIONS AND RECOMMENDATIONS}

The prototype photoneutron uranium exploration system successfully demonstrated its capability to detect plutonium in the test wells at the Hanford TRU waste sites. The excellent signal-to-background ratio (15:1 in the worst case) allowed the detection of fissile plutonium isotopes despite a neutron background from spontaneous fission and $(\alpha, n)$ emitters. Discriminating against background neutron sources is important in achieving an accurate plutonium signature. Other fissile isotopes present. such $a^{235} \mathrm{U}$. would, however, produce the same signature.

The demonstration at Hanford indicated no operational difficulties in the TRU waste site environment, and routine use by Rockwell personnel appears practical. The photoneutron probe will operate in gamma radiation fields of at least a few roentgens per hour. Because all veells at $\mathrm{Hanford}$ are cased, the probe diameter could be increased from its present $6.7 \mathrm{~cm}$. Additional gamma-ray shielding incorporated in probe construction would allow its use in even greater radiation fields. Alternatively. a large-diameter probe could be modified to increase the photoneutron source strength and the fast-neutron detection efficiency. These changes would improve the sensitivity of the method.

The interpretation of data from the photoneutron probe would be greatly enhanced by the construction of a calibration facility that simulated the environment surrounding the subsurface test wells. Such a facility should be underground. its diameter large enough to appear infinite to the interrogating neutrons. The facility should include at least two zones of differing plutonium concentrations separated by a zone barren of fissile materials. And, finally, the well should extend beyond the bottom of the model to allow the passage of the probe through all the zones of interest.

\section{ACKNOWLEDGMENTS}

The authors gratefully acknowledge the assistance of Rockwell personnel during the logging operations at Hanford. In particular. J. L. Messenger (RM) diligently looked after our health and safety, and P. J. Wiater provided valuable and timely information. The authors 
appreciate the coordination efforts of L. E. Bruns of Rockwell and L. Bali of the Grand Junction Office of DOE.

The authors commend T. Dye and T. Van Lyssel of the Los Alamos National Laboratory for their efforts in logging. We aiso acknowledge the important contributions made by R. Slice. R. Kuoppola, and L. Brewer in preparing the logging vehicle and system for the trip to Hanford.

\section{REFERENCES}

I. "Radioactive W'aste Management." Chap. 0511 and "Terminology," App. 0511. United States Atomic Energy Commission manual. September 1973.
2. M. P. Baker and T. Marks, "Photoneutron Logging System for Direct Uranium Ore-Grade Determination." Los Alamos National Laboratory refort LA-9220 (June 1982).

3. S. M. Price. R. B. Kasper, M. K. Additon, R. M. Smith. and G. V. Last. "Distribution of Plutonium and Americium Beneath the 216-Z-1A Crib: A Status Report," Rockwell-Hanford Operations report RHOST-17 (February 1979).

4. R. B. Kasper. "216-Z-12 Crib Status Report," Rockwell-Hanford Operations report RHO-LD-166 (December 1981).

5. R. B. Kasper, "Field Study of Plutonium Transport in the Vadose Zone." Rockwell-Hanford Operations report RHO-SA-224 (November 1981).

\section{APPENDIX}

\section{WELL-LOGGING DATA LISTING}

Listed below are all data obtained during the logging demonstration at the Hanford TRU waste sites. We present the data as counting rates in counts per second as a function of depth in meters. The rates are averages over the stated data recording interval (typically $15 \mathrm{~s}$ ). The format allows one-to-one correspondence between the graphical presentation of the data in the figures of the main text and the tables presented here. Each data listing refers to the appropriate figure. Note that the logging specd can be determined accurately by combining the depth information and the data-recording time interval. Also. the statistical uncertainty in a given data point can he estimated by taking the product of the data-recording time interval and the average counting rate in that interval to determine the total number of counts $(N)$ recorded in the interval. The relative standard deviation in $\mathrm{N}$ is then simply $1 / \sqrt{\mathrm{N}}$. 


\section{Well 159 \\ See Figure 5 \\ Active \\ 15 seconds per interval}

depth cnts/sec depth cnts/sec depth cnts/sec depth conts/sec

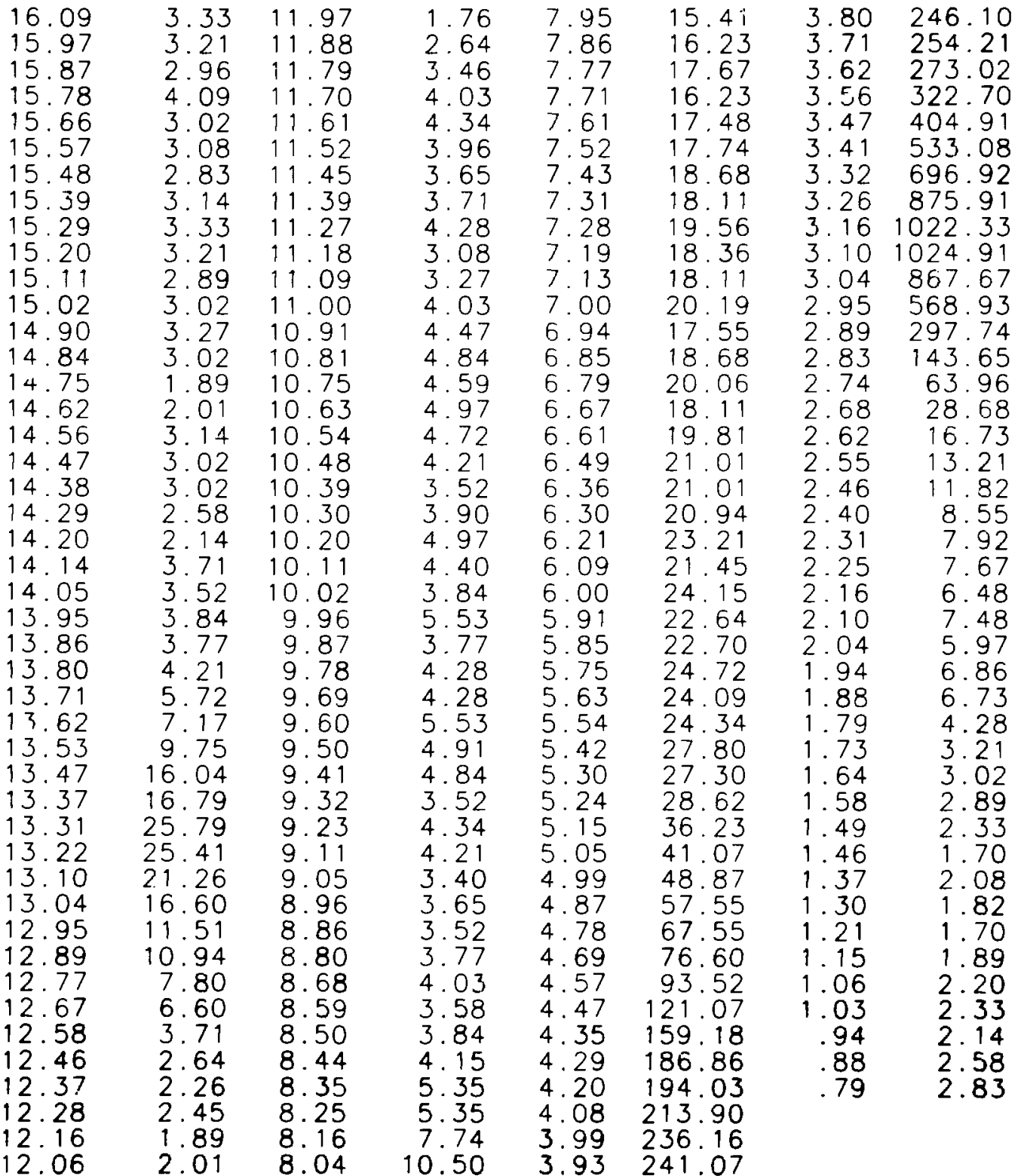




\section{Well 159 \\ See Figure 5 \\ Passive \\ 15 seconds per interval}

depth cnts/sec depth cnts/sec depth cnts/sec depth cnts/sec

\begin{tabular}{|c|c|c|c|c|c|c|c|}
\hline $\begin{array}{l}16.12 \\
16.06 \\
15.97 \\
15.81 \\
15.75 \\
15.66 \\
15.54 \\
15.48 \\
15.36 \\
15.26 \\
15.17 \\
15.08 \\
14.99 \\
14.90 \\
14.81 \\
14.72 \\
14.59 \\
14.50 \\
14.44 \\
14.32 \\
14.23 \\
14.14 \\
14.05 \\
13.95 \\
13.86 \\
13.77 \\
13.68 \\
13.56 \\
13.47 \\
13.37 \\
13.25 \\
13.16 \\
13.07 \\
12.95 \\
12.86 \\
12.77 \\
12.64 \\
12.58 \\
12.46\end{array}$ & $\begin{array}{r}.07 \\
0.00 \\
0.00 \\
0.00 \\
.07 \\
0.00 \\
0.00 \\
.07 \\
.07 \\
.20 \\
.07 \\
.07 \\
.07 \\
.07 \\
0.00 \\
0.00 \\
0.00 \\
0.00 \\
.07 \\
.07 \\
0.00 \\
.07 \\
.07 \\
0.00 \\
.13 \\
.20 \\
.20 \\
.13 \\
.13 \\
.33 \\
.13 \\
.07 \\
.07 \\
.13 \\
0.00 \\
.07 \\
0.00 \\
.20 \\
.07 \\
.07\end{array}$ & $\begin{array}{r}12.28 \\
12.16 \\
12.09 \\
11.97 \\
11.88 \\
11.79 \\
11.70 \\
11.58 \\
11.48 \\
11.39 \\
11.27 \\
11.21 \\
11.09 \\
11.00 \\
10.91 \\
10.78 \\
10.69 \\
10.63 \\
10.51 \\
10.42 \\
10.33 \\
10.24 \\
10.14 \\
10.02 \\
9.96 \\
9.87 \\
9.75 \\
9.66 \\
9.56 \\
9.47 \\
9.38 \\
9.29 \\
9.20 \\
9.11 \\
8.99 \\
8.89 \\
8.80 \\
8.71 \\
8.62 \\
8.50\end{array}$ & $\begin{array}{r}.07 \\
0.00 \\
0.00 \\
0.00 \\
.07 \\
0.00 \\
0.00 \\
0.00 \\
.07 \\
.07 \\
0.00 \\
0.00 \\
0.00 \\
0.00 \\
.07 \\
0.00 \\
0.00 \\
.07 \\
.07 \\
.07 \\
0.00 \\
.07 \\
0.00 \\
.07 \\
.13 \\
0.00 \\
0.00 \\
.07 \\
.07 \\
0.00 \\
0.00 \\
0.00 \\
0.00 \\
0.00 \\
0.00 \\
0.00 \\
.07 \\
.07 \\
0.00 \\
.07\end{array}$ & $\begin{array}{l}8.41 \\
8.35 \\
8.22 \\
8.13 \\
8.04 \\
7.95 \\
7.86 \\
7.74 \\
7.67 \\
7.58 \\
7.46 \\
7.40 \\
7.28 \\
7.19 \\
7.13 \\
7.00 \\
6.91 \\
6.82 \\
6.70 \\
6.61 \\
6.52 \\
6.39 \\
6.30 \\
6.21 \\
6.09 \\
6.00 \\
5.91 \\
5.82 \\
5.72 \\
5.60 \\
5.54 \\
5.45 \\
5.33 \\
5.24 \\
5.15 \\
5.05 \\
4.96 \\
4.84 \\
4.75 \\
4.66\end{array}$ & $\begin{array}{r}0.00 \\
.07 \\
.07 \\
.07 \\
.13 \\
.13 \\
.20 \\
.20 \\
07 \\
.33 \\
.33 \\
.07 \\
.20 \\
.13 \\
0.00 \\
.13 \\
.13 \\
.07 \\
.13 \\
.13 \\
0.00 \\
.40 \\
.27 \\
.40 \\
.20 \\
.13 \\
.13 \\
.40 \\
.53 \\
.07 \\
.27 \\
.07 \\
.27 \\
.53 \\
.60 \\
.67 \\
.47 \\
.33 \\
1.00 \\
1.27\end{array}$ & $\begin{array}{l}4.54 \\
4.41 \\
4.32 \\
4.23 \\
4.11 \\
4.02 \\
3.93 \\
3.80 \\
3.71 \\
3.62 \\
3.53 \\
3.44 \\
3.32 \\
3.22 \\
3.13 \\
3.01 \\
2.92 \\
2.83 \\
2.71 \\
2.62 \\
2.52 \\
2.43 \\
2.34 \\
2.25 \\
2.13 \\
2.07 \\
1.94 \\
1.85 \\
1.73 \\
1.64 \\
1.52 \\
1.43 \\
1.30 \\
1.18 \\
1.06 \\
.94 \\
.85 \\
.79\end{array}$ & $\begin{array}{r}1.47 \\
1.73 \\
1.87 \\
1.53 \\
1.87 \\
2.53 \\
2.67 \\
3.80 \\
6.07 \\
7.87 \\
12.07 \\
17.60 \\
21.53 \\
21.20 \\
14.73 \\
10.87 \\
5.47 \\
3.53 \\
2.13 \\
.80 \\
.87 \\
.47 \\
.33 \\
.40 \\
.33 \\
.13 \\
.20 \\
.27 \\
.13 \\
.07 \\
.13 \\
0.00 \\
0.00 \\
0.00 \\
0.00 \\
0.00 \\
0.00 \\
0.00\end{array}$ \\
\hline
\end{tabular}




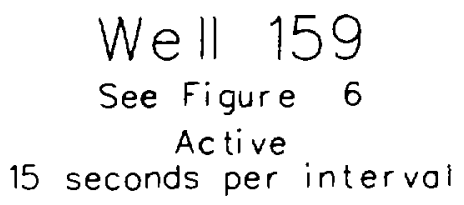

depth cnts/sec depth cnts/sec depth cnts/sec depth crits/sec

$\begin{array}{rrrrrrrr}35.78 & .55 & 27.09 & .89 & 18.46 & 1.31 & 9.93 & 3.23 \\ 35.47 & .82 & 26.69 & 1.51 & 18.10 & 1.31 & 9.56 & 3.37 \\ 35.14 & .55 & 26.33 & 1.58 & 17.76 & 1.10 & 9.23 & 3.57 \\ 34.74 & .59 & 25.96 & .96 & 17.43 & 1.24 & 8.83 & 2.89 \\ 34.41 & 1.24 & 25.60 & 1.10 & 17.06 & 1.92 & 8.47 & 2.54 \\ 34.04 & 1.17 & 25.23 & .96 & 16.73 & 1.86 & 8.10 & 4.60 \\ 33.64 & .62 & 24.87 & .89 & 16.39 & 1.44 & 7.74 & 14.23 \\ 33.28 & 1.58 & 24.50 & .96 & 16.03 & 1.58 & 7.34 & 17.39 \\ 32.91 & .69 & 24.10 & 1.24 & 15.66 & 1.86 & 6.97 & 18.08 \\ 32.55 & .89 & 23.74 & 1.24 & 15.36 & 1.17 & 6.61 & 18.97 \\ 32.18 & .82 & 23.40 & .55 & 15.02 & 1.99 & 6.24 & 19.04 \\ 31.82 & 1.17 & 23.01 & 1.03 & 14.65 & 1.58 & 5.91 & 19.66 \\ 31.42 & 1.17 & 22.67 & .89 & 14.29 & 1.37 & 5.54 & 22.68 \\ 31.05 & 1.10 & 22.31 & 1.10 & 13.95 & 1.44 & 5.15 & 25.84 \\ 30.69 & 1.03 & 21.91 & .55 & 13.59 & 5.09 & 4.78 & 49.21 \\ 30.32 & 1.24 & 21.54 & 1.51 & 13.22 & 18.14 & 4.38 & 101.31 \\ 29.99 & 1.24 & 21.18 & 1.72 & 12.86 & 16.77 & 4.02 & 192.16 \\ 29.65 & 1.44 & 20.84 & .55 & 12.49 & 5.15 & 3.65 & 241.24 \\ 29.25 & .96 & 20.51 & .76 & 12.12 & 1.44 & 3.29 & 477.73 \\ 28.92 & 1.03 & 20.14 & .76 & 11.76 & 1.24 & 2.86 & 809.42 \\ 28.55 & 1.03 & 19.81 & .96 & 11.39 & 2.27 & 2.52 & 60.07 \\ 28.19 & .55 & 19.47 & 1.31 & 11.03 & 1.44 & 2.13 & 8.32 \\ 27.82 & .96 & 19.14 & 1.17 & 10.66 & 2.68 & 1.76 & 5.22 \\ 27.46 & .62 & 18.80 & .96 & 10.33 & 2.89 & 1.40 & 2.47\end{array}$




\section{Well 175 \\ See Figure 7 \\ Active \\ 15 seconds per interval}

depth cnts/sec depth cnts/sec depth cnts/sec depth cnts/sec

$\begin{array}{rrrrrrrr}9.25 & 2.13 & 6.81 & 6.33 & 4.61 & 83.47 & 2.66 & 15.20 \\ 9.16 & 2.07 & 6.72 & 6.20 & 4.55 & 80.00 & 2.57 & 8.80 \\ 9.10 & 3.00 & 6.66 & 5.33 & 4.52 & 83.33 & 2.51 & 4.67 \\ 9.00 & 3.00 & 6.57 & 5.73 & 4.43 & 86.00 & 2.45 & 2.07 \\ 8.91 & 2.73 & 6.50 & 7.73 & 4.37 & 88.87 & 2.39 & 1.53 \\ 8.82 & 3.20 & 6.41 & 6.73 & 4.31 & 87.93 & 2.30 & 1.47 \\ 8.76 & 2.87 & 6.32 & 8.13 & 4.22 & 89.40 & 2.24 & 1.20 \\ 8.64 & 3.53 & 6.23 & 10.80 & 4.16 & 92.13 & 2.15 & 1.07 \\ 8.58 & 1.80 & 6.17 & 10.73 & 4.07 & 96.20 & 2.08 & 2.00 \\ 8.49 & 3.33 & 6.08 & 11.47 & 4.01 & 102.53 & 1.99 & 1.47 \\ 8.39 & 2.53 & 5.99 & 13.87 & 3.94 & 107.33 & 1.93 & 1.40 \\ 8.33 & 3.00 & 5.93 & 18.67 & 3.88 & 108.40 & 1.90 & 1.53 \\ 8.24 & 2.67 & 5.86 & 25.40 & 3.82 & 103.47 & 1.84 & 2.00 \\ 8.18 & 3.33 & 5.77 & 36.00 & 3.76 & 116.27 & 1.78 & 1.73 \\ 8.09 & 2.87 & 5.71 & 41.73 & 3.73 & 125.47 & 1.72 & 1.53 \\ 8.03 & 3.20 & 5.65 & 50.87 & 3.64 & 132.33 & 1.66 & 1.07 \\ 7.94 & 3.20 & 5.59 & 68.87 & 3.61 & 138.47 & 1.63 & .93 \\ 7.88 & 3.67 & 5.53 & 86.40 & 3.55 & 142.73 & 1.54 & .80 \\ 7.82 & 3.33 & 5.44 & 113.33 & 3.46 & 154.73 & 1.48 & 1.00 \\ 7.72 & 4.07 & 5.38 & 127.20 & 3.43 & 165.80 & 1.41 & .93 \\ 7.69 & 3.67 & 5.29 & 129.07 & 3.33 & 182.73 & 1.32 & 1.33 \\ 7.60 & 5.00 & 5.19 & 131.13 & 3.30 & 197.40 & 1.26 & .60 \\ 7.54 & 3.27 & 5.13 & 130.80 & 3.21 & 211.87 & 1.17 & .80 \\ 7.45 & 2.67 & 5.07 & 124.47 & 3.15 & 217.27 & 1.11 & 1.07 \\ 7.39 & 2.67 & 5.01 & 120.80 & 3.09 & 206.93 & 1.02 & .93 \\ 7.30 & 3.00 & 4.98 & 110.80 & 3.00 & 190.47 & .96 & .93 \\ 7.24 & 3.87 & 4.89 & 107.87 & 2.94 & 147.93 & .87 & .67 \\ 7.14 & 3.87 & 4.83 & 98.53 & 2.85 & 105.27 & .84 & .93 \\ 7.08 & 4.00 & 4.80 & 89.67 & 2.82 & 65.87 & .74 & .67 \\ 6.96 & 4.40 & 4.74 & 84.20 & 2.76 & 43.00 & .68 & .67 \\ 6.90 & 4.87 & 4.68 & 86.73 & 2.69 & 27.53 & .59 & .80\end{array}$




\section{Well 175 \\ See figure 7 \\ Possive \\ 15 seconds per intervol}

depth cnts/sec depth cots/sec depth cnts/sec depth crits/sec

$\begin{array}{lrrrrrrr}9.25 & 0.00 & 7.17 & 0.00 & 5.07 & .80 & 2.63 & .27 \\ 9.16 & 0.00 & 7.11 & 0.00 & 4.98 & 1.27 & 2.57 & .20 \\ 9.10 & .07 & 7.05 & .07 & 4.92 & 1.33 & 2.51 & .07 \\ 9.00 & 0.00 & 6.96 & .13 & 4.83 & 1.00 & 2.42 & 0.00 \\ 8.94 & .07 & 6.90 & .33 & 4.77 & .87 & 2.36 & 0.00 \\ 8.85 & .20 & 6.81 & .20 & 4.68 & .93 & 2.27 & 0.00 \\ 8.79 & .07 & 6.78 & 0.00 & 4.58 & 1.27 & 2.24 & 0.00 \\ 8.70 & 0.00 & 6.69 & .07 & 4.49 & .73 & 2.15 & .07 \\ 8.64 & 0.00 & 6.63 & .07 & 4.40 & .73 & 2.08 & 0.00 \\ 8.58 & .07 & 6.57 & .13 & 4.34 & .60 & 1.99 & 0.00 \\ 8.49 & .07 & 6.50 & .13 & 4.25 & .60 & 1.93 & 0.00 \\ 8.42 & .20 & 6.44 & .07 & 4.19 & .87 & 1.87 & 0.00 \\ 8.36 & 0.00 & 6.38 & .13 & 4.07 & .73 & 1.78 & .07 \\ 8.30 & 0.00 & 6.35 & .13 & 4.01 & .87 & 1.72 & .07 \\ 8.24 & .07 & 6.29 & .07 & 3.91 & .87 & 1.63 & 0.00 \\ 8.18 & 0.00 & 6.23 & .27 & 3.85 & 1.20 & 1.57 & 0.00 \\ 8.12 & 0.00 & 6.17 & .40 & 3.75 & 1.27 & 1.51 & .07 \\ 8.03 & .13 & 6.11 & .13 & 3.70 & 1.87 & 1.44 & 0.00 \\ 8.00 & .07 & 6.05 & .53 & 3.61 & 1.33 & 1.35 & 0.00 \\ 7.94 & .20 & 5.96 & .13 & 3.55 & 2.53 & 1.29 & 0.00 \\ 7.88 & .07 & 5.89 & .27 & 3.46 & 2.20 & 1.23 & 0.00 \\ 7.85 & .07 & 5.83 & .53 & 3.40 & 1.93 & 1.17 & 0.00 \\ 7.75 & 0.00 & 5.74 & .73 & 3.33 & 3.13 & 1.08 & 0.00 \\ 7.72 & .13 & 5.68 & .67 & 3.27 & 3.20 & .99 & 0.00 \\ 7.66 & .07 & 5.62 & .47 & 3.18 & 2.53 & .93 & 0.00 \\ 7.60 & 0.00 & 5.56 & .93 & 3.15 & 2.33 & .87 & 0.00 \\ 7.57 & .07 & 5.47 & .47 & 3.06 & 1.93 & .80 & 0.00 \\ 7.48 & .07 & 5.41 & .93 & 3.00 & 2.00 & .71 & 0.00 \\ 7.42 & 0.00 & 5.32 & 1.20 & 2.94 & 1.60 & .65 & .07 \\ 7.36 & .07 & 5.29 & 1.47 & 2.85 & .93 & .59 & .07 \\ 7.30 & 0.00 & 5.19 & 1.20 & 2.79 & .87 & & \\ 7.27 & .07 & 5.13 & 1.07 & 2.69 & .60 & & \end{array}$




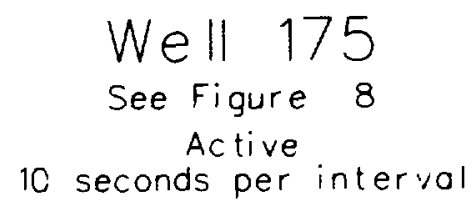

depth =nts/sec depth cnts/sec depth cnts/sec depth cnts/sec

$\begin{array}{llllllll}35.16 & 2.19 & 31.04 & 1.62 & 27.08 & .95 & 23.02 & 1.62 \\ 35.00 & 1.14 & 30.83 & 1.62 & 26.90 & 1.90 & 22.81 & 2.57 \\ 34.85 & 1.62 & 30.58 & 1.52 & 26.65 & 2.29 & 22.57 & 1.14 \\ 34.61 & 1.05 & 30.40 & 2.00 & 26.47 & 1.71 & 22.35 & .76 \\ 34.36 & 1.33 & 30.16 & 2.48 & 26.22 & 1.33 & 22.11 & 1.05 \\ 34.12 & 2.29 & 29.94 & 1.24 & 26.01 & 1.62 & 21.90 & 2.38 \\ 33.88 & 1.81 & 29.70 & 1.52 & 25.77 & 1.90 & 21.65 & 1.52 \\ 33.63 & 1.81 & 29.52 & 2.29 & 25.55 & 2.00 & 21.41 & 1.90 \\ 33.39 & 1.24 & 29.27 & 2.00 & 25.31 & 1.81 & 21.17 & 2.57 \\ 33.14 & 1.43 & 29.06 & 2.48 & 25.10 & 1.62 & 20.95 & 1.81 \\ 32.90 & 2.00 & 28.85 & 2.76 & 21.88 & 2.00 & 20.68 & 2.19 \\ 32.69 & 2.57 & 28.63 & 1.71 & 24.64 & 2.10 & 20.46 & 1.71 \\ 32.41 & 1.62 & 28.42 & 2.19 & 24.40 & 1.52 & 20.22 & 1.71 \\ 32.17 & 2.00 & 28.18 & 2.00 & 24.18 & 1.24 & 19.98 & 3.05 \\ 31.96 & 2.48 & 27.99 & 2.29 & 23.94 & 2.00 & 19.76 & 1.71 \\ 31.71 & 2.38 & 27.75 & 2.10 & 23.73 & 1.90 & 19.58 & 1.43 \\ 31.50 & 1.52 & 27.54 & 1.24 & 23.48 & 1.81 & & \\ 31.25 & 1.71 & 27.32 & 1.33 & 23.27 & 1.90 & & \end{array}$




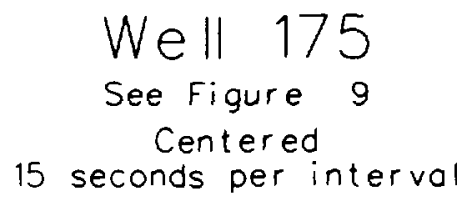

depth cnts/sec deptr: cnts/sec depth cnts/sec depth chts/sec

$\begin{array}{rrrrrrrr}7.72 & 3.37 & 5.83 & 28.48 & 4.01 & 92.38 & 2.21 & 1.30 \\ 7.69 & 3.96 & 5.74 & 34.58 & 3.91 & 103.15 & 2.12 & 2.01 \\ 7.63 & 4.48 & 5.68 & 48.13 & 3.85 & 111.64 & 2.05 & 2.21 \\ 7.54 & 2.66 & 5.59 & 66.17 & 3.76 & 116.64 & 1.93 & 1.95 \\ 7.45 & 2.98 & 5.50 & 86.28 & 3.67 & 133.12 & 1.87 & 2.14 \\ 7.36 & 3.70 & 5.44 & 106.00 & 3.61 & 152.84 & 1.78 & 2.53 \\ 7.27 & 4.54 & 5.35 & 105.09 & 3.52 & 167.82 & 1.72 & 2.14 \\ 7.17 & 5.00 & 5.25 & 115.08 & 3.43 & 185.60 & 1.63 & 2.01 \\ 7.08 & 4.67 & 5.16 & 110.15 & 3.33 & 212.91 & 1.54 & 1.17 \\ 6.99 & 5.38 & 5.10 & 109.70 & 3.27 & 224.98 & 1.48 & 1.62 \\ 6.90 & 4.67 & 4.98 & 102.37 & 3.18 & 223.55 & 1.38 & 2.08 \\ 6.81 & 6.23 & 4.92 & 95.49 & 3.09 & 213.10 & 1.32 & 1.23 \\ 6.72 & 5.32 & 4.83 & 87.77 & 3.00 & 174.57 & 1.20 & 2.08 \\ 6.63 & 7.20 & 4.74 & 84.14 & 2.94 & 120.14 & 1.14 & 1.62 \\ 6.53 & 7.07 & 4.68 & 79.14 & 2.85 & 71.29 & 1.05 & 1.43 \\ 6.44 & 6.81 & 4.58 & 79.34 & 2.79 & 36.20 & .99 & 1.23 \\ 6.35 & 9.02 & 4.52 & 77.72 & 2.69 & 18.10 & .90 & 1.43 \\ 6.26 & 9.67 & 4.43 & 80.57 & 2.60 & 8.04 & .80 & 1.49 \\ 6.20 & 8.95 & 4.34 & 85.31 & 2.54 & 4.15 & .71 & 1.62 \\ 6.08 & 12.26 & 4.25 & 87.64 & 2.45 & 2.53 & .68 & 1.56 \\ 6.02 & 14.66 & 4.19 & 88.23 & 2.39 & 2.27 & & \\ 5.93 & 18.81 & 4.07 & 93.22 & 2.27 & 1.49 & & \end{array}$




\section{We $\| 175$}

See Figure 9

Sidewalled

15 seconds per interval

depth cnts/sec depth cnts/sec depth cnts/sec depth cnts/sec

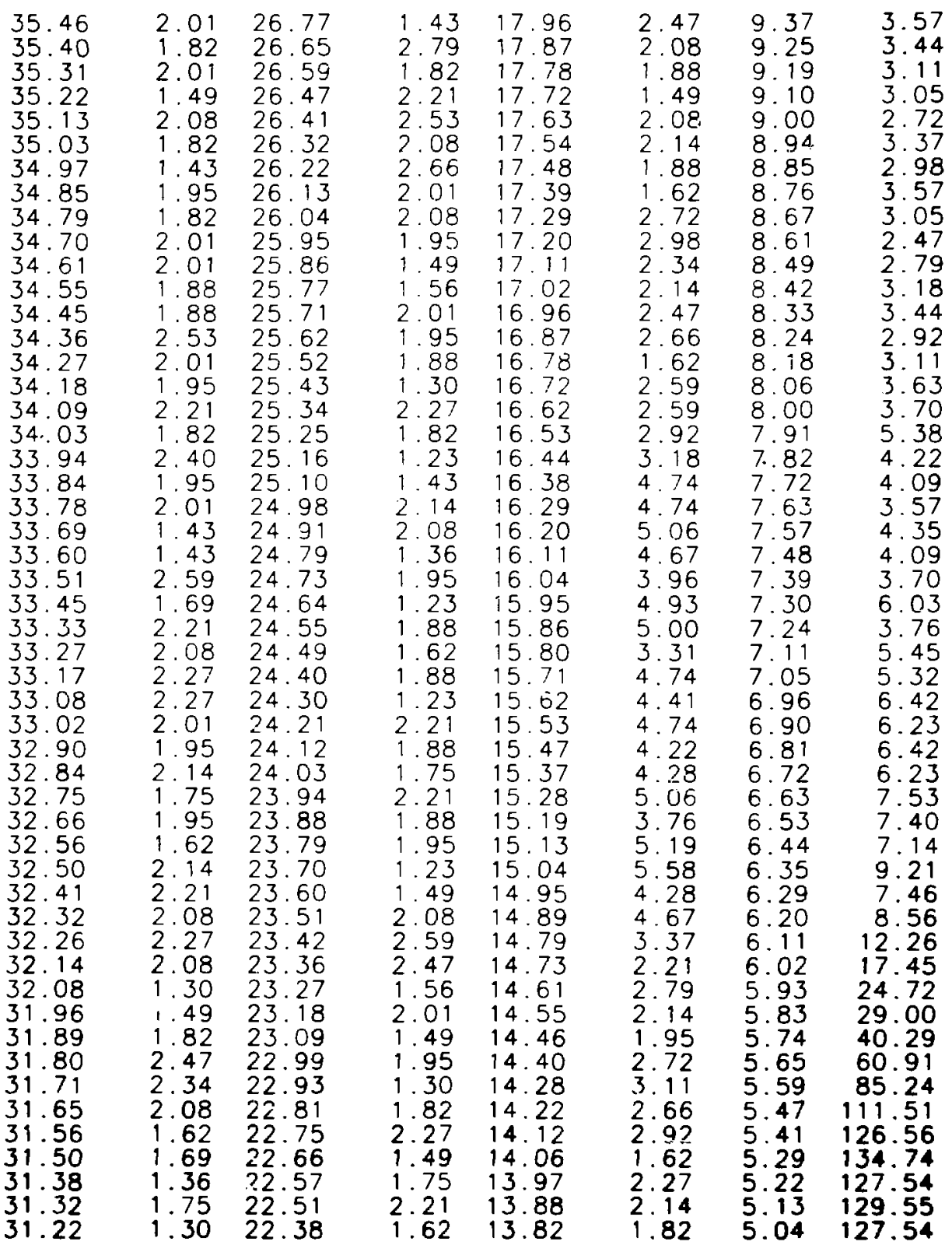




\section{We $l$ 175 \\ Sidewalled \\ 15 seconds per interval \\ (continued)}

depth cnts/sec depth cnts/sec depth cnts/sec depth conts/sec

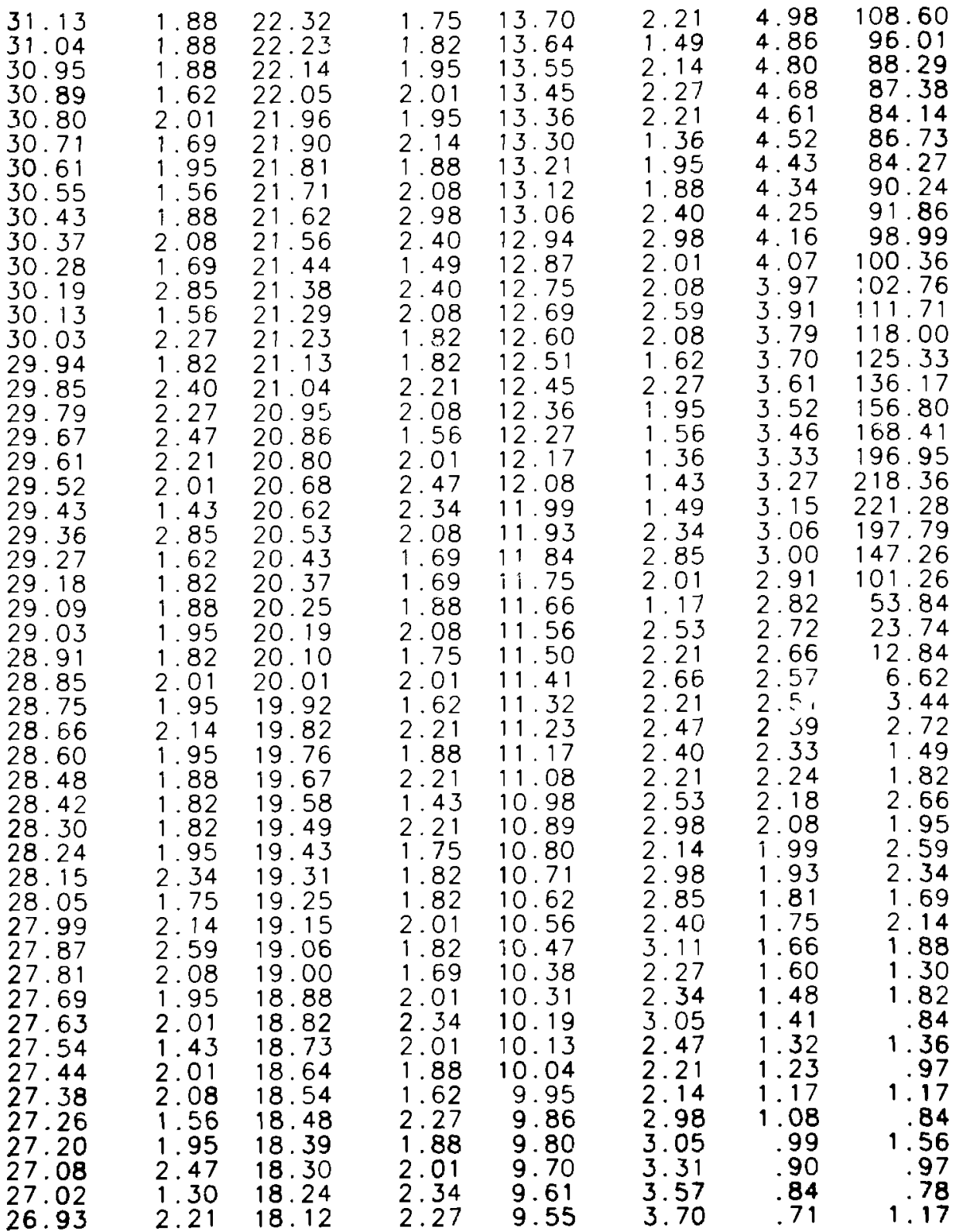




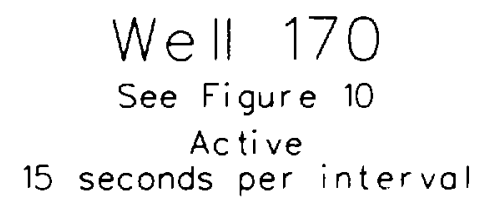

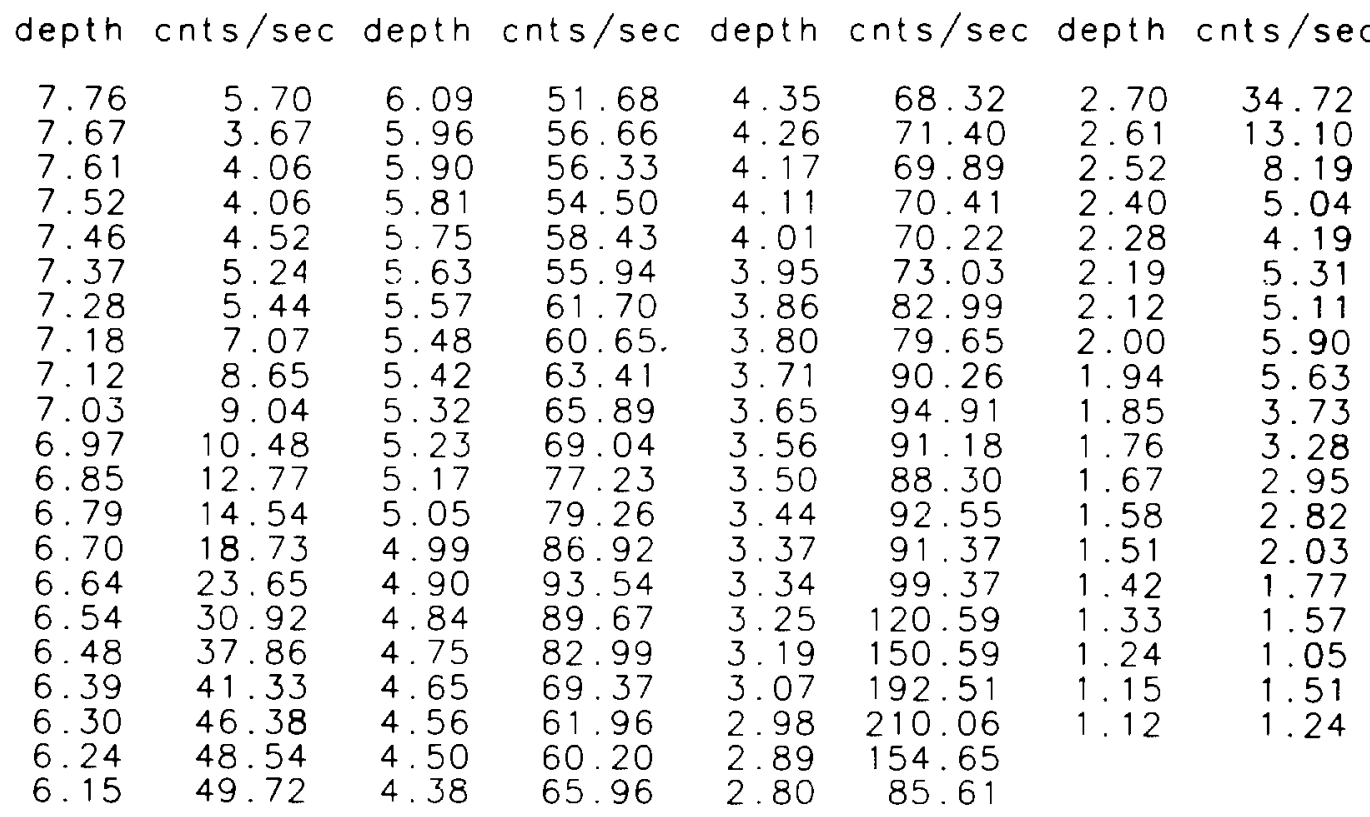




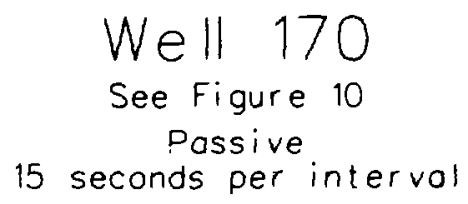

depth chts/sec depth cnts/sec depth cnts/sec depth cnts/sec

$\begin{array}{lrrrrrrr}7.76 & .13 & 6.06 & .59 & 4.44 & .66 & 2.76 & .98 \\ 7.67 & .07 & 6.00 & .85 & 4.38 & .59 & 2.70 & .39 \\ 7.61 & 0.00 & 5.93 & .46 & 4.29 & .59 & 2.61 & .33 \\ 7.52 & .07 & 5.87 & .72 & 4.26 & .85 & 2.55 & .07 \\ 7.46 & 0.00 & 5.81 & .33 & 4.17 & .79 & 2.46 & .20 \\ 7.34 & .13 & 5.72 & 1.05 & 4.11 & .59 & 2.43 & .07 \\ 7.28 & .13 & 5.63 & .46 & 4.04 & 1.05 & 2.34 & 0.00 \\ 7.18 & 0.00 & 5.54 & .46 & 3.98 & 1.18 & 2.28 & .07 \\ 7.15 & .13 & 5.48 & .66 & 3.92 & .85 & 2.19 & .13 \\ 7.06 & .07 & 5.42 & .20 & 3.83 & .72 & 2.09 & .13 \\ 7.00 & .20 & 5.36 & .33 & 3.80 & 1.11 & 2.00 & .13 \\ 6.88 & .07 & 5.29 & .59 & 3.71 & 1.24 & 1.97 & 0.00 \\ 6.82 & .20 & 5.23 & .85 & 3.65 & .98 & 1.88 & 0.00 \\ 6.73 & .33 & 5.17 & .85 & 3.53 & 1.44 & 1.82 & 0.00 \\ 6.64 & .33 & 5.11 & .92 & 3.47 & 1.51 & 1.76 & 0.00 \\ 6.57 & .66 & 5.02 & .92 & 3.37 & 1.70 & 1.67 & 0.00 \\ 6.51 & .46 & 4.96 & 1.24 & 3.31 & 3.01 & 1.61 & 0.00 \\ 6.42 & .26 & 4.87 & .72 & 3.22 & 3.08 & 1.51 & .07 \\ 6.39 & .46 & 4.81 & .92 & 3.16 & 2.55 & 1.45 & 0.00 \\ 6.30 & .72 & 4.72 & .59 & 3.07 & 2.23 & 1.36 & .07 \\ 6.24 & .72 & 4.68 & .59 & 3.01 & 3.01 & 1.30 & .13 \\ 6.18 & .39 & 4.59 & .59 & 2.92 & 1.57 & 1.21 & 0.00 \\ 6.12 & 1.11 & 4.53 & .85 & 2.86 & 1.05 & 1.15 & 0.00\end{array}$




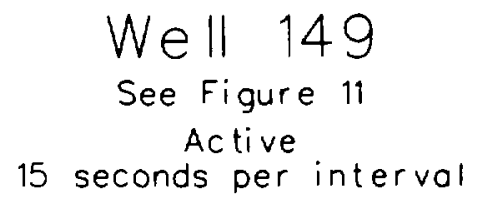

depth cnts/sec depth cnts/sec depth cnts/sec depth cnts/sec

$\begin{array}{lrrrrrrr}6.82 & 3.21 & 5.08 & 40.68 & 3.40 & 242.81 & 1.82 & 9.08 \\ 6.73 & 2.47 & 5.02 & 42.28 & 3.31 & 316.69 & 1.73 & 6.81 \\ 6.70 & 3.14 & 4.90 & 45.09 & 3.22 & 360.78 & 1.67 & 4.74 \\ 6.57 & 4.61 & 4.84 & 41.55 & 3.16 & 343.14 & 1.58 & 4.07 \\ 6.51 & 4.68 & 4.72 & 42.55 & 3.04 & 261.32 & 1.51 & 3.34 \\ 6.39 & 7.28 & 4.62 & 42.22 & 3.01 & 170.40 & 1.42 & 2.20 \\ 6.33 & 10.9 & 4.56 & 38.61 & 2.89 & 97.13 & 1.36 & .80 \\ 6.24 & 11.42 & 4.47 & 44.09 & 2.80 & 42.62 & 1.27 & 1.14 \\ 6.18 & 13.43 & 4.38 & 46.63 & 2.73 & 18.97 & 1.21 & .94 \\ 6.09 & 15.50 & 4.29 & 55.11 & 2.64 & 9.49 & 1.09 & 1.54 \\ 6.03 & 18.90 & 4.23 & 60.72 & 2.58 & 6.95 & 1.00 & 1.27 \\ 5.93 & 18.24 & 4.14 & 60.25 & 2.49 & 5.74 & .91 & 1.07 \\ 5.81 & 20.37 & 4.08 & 72.61 & 2.40 & 5.68 & .81 & 1.87 \\ 5.75 & 21.38 & 3.98 & 75.42 & 2.34 & 7.55 & .75 & 1.14 \\ 5.63 & 21.98 & 3.89 & 72.48 & 2.28 & 8.28 & .63 & 1.27 \\ 5.57 & 27.05 & 3.80 & 73.88 & 2.19 & 12.42 & .57 & 1.20 \\ 5.48 & 27.39 & 3.71 & 89.84 & 2.12 & 13.43 & .54 & 1.34 \\ 5.36 & 31.06 & 3.65 & 111.49 & 2.03 & 12.02 & & \\ 5.29 & 35.34 & .3 .59 & 147.36 & 1.97 & 13.43 & & \\ 5.17 & 38.68 & 3.50 & 184.77 & 1.88 & 12.56 & & \end{array}$




\section{We II 149 \\ See Figure 11 \\ Passive \\ 15 seconds per interval}

depth cnts/sec depth cnts/sec depth cnts/sec depth cnts/sec

$\begin{array}{lrrrrrrr}6.85 & .07 & 5.17 & .27 & 3.40 & 7.35 & 1.82 & .07 \\ 6.79 & 0.00 & 5.08 & .40 & 3.31 & 8.28 & 1.76 & .20 \\ 6.70 & .13 & 4.99 & .80 & 3.22 & 7.75 & 1.67 & .13 \\ 6.61 & .07 & 4.90 & 1.00 & 3.13 & 5.74 & 1.61 & .20 \\ 6.54 & 0.00 & 4.81 & .73 & 3.04 & 3.81 & 1.51 & 0.00 \\ 6.42 & .07 & 4.72 & .27 & 2.92 & 2.14 & 1.45 & .07 \\ 6.36 & .27 & 4.62 & .40 & 2.89 & 1.34 & 1.36 & 0.00 \\ 6.27 & 0.00 & 4.53 & .67 & 2.80 & 1.20 & 1.30 & 0.00 \\ 6.18 & .27 & 4.44 & .87 & 2.73 & 1.00 & 1.21 & 0.00 \\ 6.09 & .07 & 4.35 & 1.34 & 2.64 & .27 & 1.15 & 0.00 \\ 6.03 & .20 & 4.26 & .60 & 2.58 & .40 & 1.06 & 0.00 \\ 5.93 & .20 & 4.20 & 1.14 & 2.52 & .40 & 1.00 & 0.00 \\ 5.84 & .40 & 4.11 & 2.00 & 2.43 & .33 & .91 & 0.00 \\ 5.75 & .27 & 4.01 & 1.34 & 2.37 & .33 & .84 & 0.00 \\ 5.66 & .07 & 3.92 & 1.54 & 2.28 & .33 & .75 & 0.00 \\ 5.60 & .13 & 3.87 & 1.40 & 2.22 & .07 & .69 & 0.00 \\ 5.48 & .33 & 3.77 & 2.67 & 2.12 & .33 & .63 & 0.00 \\ 5.42 & .27 & 3.65 & 3.94 & 2.06 & .33 & .54 & 0.00 \\ 5.32 & .67 & 3.59 & 4.68 & 1.97 & .20 & & \\ 5.23 & .73 & 3.50 & 8.35 & 1.91 & .07 & & \end{array}$




\section{Well 361 \\ See Figure 12 \\ Active \\ 15 \\ seconds per intervol}

depth cnts/sec depth cnts/sec depth cnts/sec depth cnts/sec

$\begin{array}{rrrrrrrr}5.60 & 90.30 & 4.38 & 34.78 & 3.10 & 3.21 & 1.85 & 2.80 \\ 5.54 & 95.89 & 4.35 & 38.06 & 3.04 & 3.61 & 1.82 & 2.93 \\ 5.48 & 88.80 & 4.26 & 37.78 & 3.01 & 4.50 & 1.73 & 2.93 \\ 5.45 & 79.32 & 4.23 & 36.42 & 2.95 & 4.23 & 1.67 & 3.14 \\ 5.45 & 77.07 & 4.17 & 27.01 & 2.89 & 3.41 & 1.64 & 2.25 \\ 5.39 & 76.52 & 4.11 & 15.28 & 2.83 & 3.14 & 1.58 & 2.25 \\ 5.36 & 70.31 & 4.08 & 10.30 & 2.76 & 3.82 & 1.51 & 2.18 \\ 5.32 & 71.34 & 3.98 & 9.68 & 2.73 & 2.32 & 1.45 & 2.93 \\ 5.26 & 85.25 & 3.95 & 7.09 & 2.67 & 4.43 & 1.39 & 2.32 \\ 5.20 & 100.80 & 3.89 & 7.02 & 2.61 & 3.61 & 1.33 & 2.93 \\ 5.14 & 114.58 & 3.83 & 7.09 & 2.58 & 3.21 & 1.30 & 2.25 \\ 5.08 & 97.80 & 3.80 & 6.89 & 2.52 & 3.68 & 1.24 & 2.32 \\ 5.02 & 90.16 & 3.74 & 5.46 & 2.43 & 3.21 & 1.21 & 2.46 \\ 4.99 & 76.38 & 3.68 & 6.14 & 2.40 & 3.21 & 1.15 & 2.39 \\ 4.93 & 68.95 & 3.62 & 6.41 & 2.34 & 3.41 & 1.06 & 1.50 \\ 4.87 & 59.54 & 3.56 & 6.27 & 2.28 & 3.21 & 1.03 & 1.84 \\ 4.81 & 54.63 & 3.50 & 5.66 & 2.25 & 2.52 & .97 & .95 \\ 4.75 & 58.58 & 3.47 & 5.12 & 2.19 & 2.18 & .91 & 1.71 \\ 4.72 & 56.67 & 3.40 & 4.77 & 2.12 & 3.00 & .87 & 2.32 \\ 4.62 & 58.58 & 3.34 & 4.84 & 2.06 & 2.73 & .81 & 1.30 \\ 4.56 & 59.95 & 3.31 & 5.05 & 2.00 & 2.39 & .75 & 1.23 \\ 4.53 & 60.36 & 3.25 & 4.77 & 1.97 & 2.52 & .72 & 1.30 \\ 4.50 & 46.51 & 3.19 & 4.50 & 1.94 & 3.48 & .63 & 1.50 \\ 4.44 & 45.97 & 3.19 & 4.16 & 1.91 & 2.80 & .60 . & 1.77\end{array}$




\section{Well 361 \\ See Figure 12 \\ Possive \\ 15 seconds per interval}

$\begin{array}{rrrrrrrr}\text { depth cnts/sec depth cnts/sec depth cnts/sec depth cnts/sec } \\ 5.60 & 3.00 & 4.53 & 2.39 & 3.34 & 3.21 & 1.91 & 2.52 \\ 5.57 & 3.41 & 4.47 & 2.59 & 3.28 & 3.68 & 1.82 & 2.11 \\ 5.51 & 3.61 & 4.44 & 3.00 & 3.22 & 3.21 & 1.76 & 1.84 \\ 5.48 & 3.21 & 4.38 & 2.86 & 3.16 & 2.25 & 1.67 & 2.05 \\ 5.42 & 4.36 & 4.32 & 3.61 & 3.10 & 3.34 & 1.61 & 1.84 \\ 5.42 & 4.30 & 4.26 & 4.50 & 3.04 & 3.55 & 1.55 & 1.98 \\ 5.32 & 4.98 & 4.23 & 3.48 & 2.95 & 2.32 & 1.48 & 2.05 \\ 5.29 & 5.59 & 4.17 & 3.82 & 2.89 & 2.11 & 1.39 & 1.43 \\ 5.23 & 4.36 & 4.11 & 3.89 & 2.83 & 3.00 & 1.33 & 1.64 \\ 5.17 & 4.16 & 4.04 & 2.93 & 2.73 & 2.66 & 1.24 & 1.64 \\ 5.14 & 3.21 & 3.98 & 3.61 & 2.67 & 2.46 & 1.18 & 1.71 \\ 5.08 & 2.73 & 3.95 & 4.50 & 2.58 & 2.39 & 1.12 & 1.09 \\ 5.02 & 2.59 & 3.86 & 4.57 & 2.55 & 1.91 & 1.06 & 1.09 \\ 4.96 & 1.77 & 3.80 & 3.55 & 2.46 & 3.27 & .97 & 1.16 \\ 4.90 & 1.91 & 3.74 & 3.55 & 2.40 & 2.80 & .91 & .68 \\ 4.87 & 2.18 & 3.68 & 4.64 & 2.31 & 2.52 & .81 & .41 \\ 4.81 & 1.98 & 3.65 & 3.34 & 2.28 & 1.91 & .75 & .20 \\ 4.75 & 1.77 & 3.59 & 3.48 & 2.19 & 1.71 & .69 & .20 \\ 4.68 & 1.91 & 3.50 & 3.21 & 2.12 & 2.25 & .60 & .20 \\ 4.62 & 1.91 & 3.47 & 3.34 & 2.03 & 2.32 & & \\ 4.56 & 2.52 & 3.40 & 3.61 & 1.97 & 1.98 & & \end{array}$




\section{Uranium Well 19-3 \\ See Figure 13 \\ Active \\ 10 seconds per interval}

depth cnts/sec depth cnts/sec depth ints/sec depth $\mathrm{cnts} / \mathrm{sec}$

\begin{tabular}{|c|c|c|c|c|c|c|c|}
\hline $\begin{array}{l}56.53 \\
56.32 \\
56.07 \\
55.86 \\
55.62\end{array}$ & 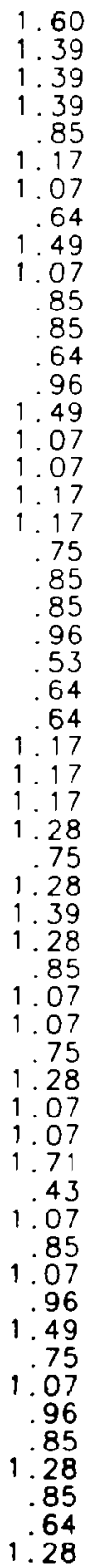 & $\begin{array}{l}43.27 \\
43.03 \\
42.82 \\
42.54 \\
42.30 \\
42.05 \\
41.78 \\
41.57 \\
41.29 \\
41.05 \\
40.80 \\
40.53 \\
40.29 \\
40.04 \\
39.77 \\
39.55 \\
39.31 \\
39.07 \\
38.82 \\
38.55 \\
38.33 \\
38.09 \\
37.85 \\
37.60 \\
37.33 \\
37.09 \\
36.87 \\
36.60 \\
36.32 \\
36.11 \\
35.84 \\
35.59 \\
35.35 \\
35.10 \\
34.86 \\
34.59 \\
34.37 \\
34.13 \\
33.82 \\
33.61 \\
33.34 \\
33.06 \\
32.82 \\
32.57 \\
32.30 \\
32.03 \\
31.78 \\
31.54 \\
31.26 \\
30.99 \\
30.75 \\
30.47 \\
30.23 \\
29.98 \\
29.71 \\
29.43\end{array}$ & $\begin{array}{r}.85 \\
.96 \\
.96 \\
1.07 \\
.75 \\
.64 \\
1.39 \\
1.17 \\
.53 \\
.85 \\
1.07 \\
1.07 \\
.64 \\
.96 \\
.96 \\
1.39 \\
1.71 \\
.85 \\
.96 \\
.96 \\
.64 \\
1.07 \\
1.49 \\
.53 \\
.96 \\
.75 \\
.96 \\
.53 \\
.75 \\
.75 \\
1.07 \\
.64 \\
.85\end{array}$ & $\begin{array}{l}29.19 \\
28.92 \\
28.64 \\
28.37 \\
28.12 \\
27.88 \\
27.64 \\
27.39 \\
27.12 \\
26.87 \\
26.63 \\
26.36 \\
26.08 \\
25.81 \\
25.56 \\
25.29 \\
25.05 \\
24.80 \\
24.53 \\
24.25 \\
24.01 \\
23.73 \\
23.49 \\
23.25 \\
23.00 \\
22.70 \\
22.42 \\
22.18 \\
21.94 \\
21.63 \\
21.39 \\
21.14 \\
20.87 \\
20.63 \\
20.35 \\
20.11 \\
19.83 \\
19.59 \\
19.32 \\
19.04 \\
18.77 \\
18.52 \\
18.28 \\
18.00 \\
17.73 \\
17.49 \\
17.24 \\
17.00 \\
16.75 \\
16.48 \\
16.24 \\
15.99 \\
15.72 \\
15.47 \\
15.20 \\
14.93\end{array}$ & 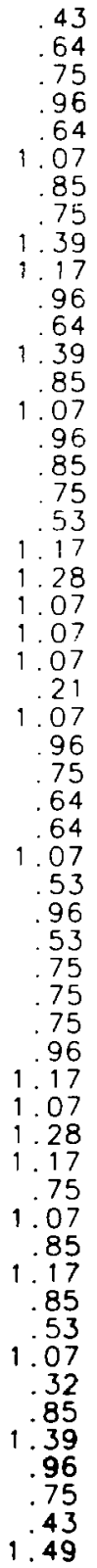 & 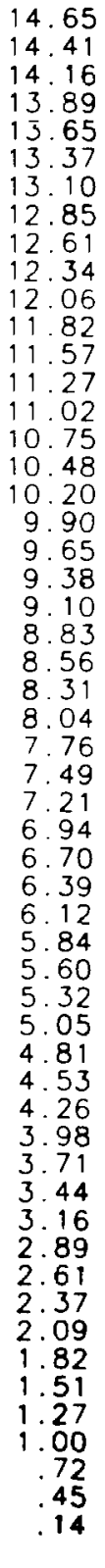 & $\begin{array}{r}.85 \\
.64 \\
1.49 \\
.85 \\
.96 \\
.75 \\
.96 \\
.43 \\
.53 \\
.21 \\
.96 \\
1.49 \\
.75 \\
.75 \\
1.28 \\
1.07 \\
1.17 \\
.85 \\
.75 \\
1.60 \\
.85 \\
1.17 \\
.75 \\
.43 \\
1.28 \\
.96 \\
1.28 \\
1.69 \\
1.64 \\
1.28 \\
.85\end{array}$ \\
\hline
\end{tabular}




\section{Well 181 \\ See Figure 14 \\ Active \\ 15 seconds per interval}

depth cnts/sec depth chts/sec depth cnts/sec depth cnts/sec

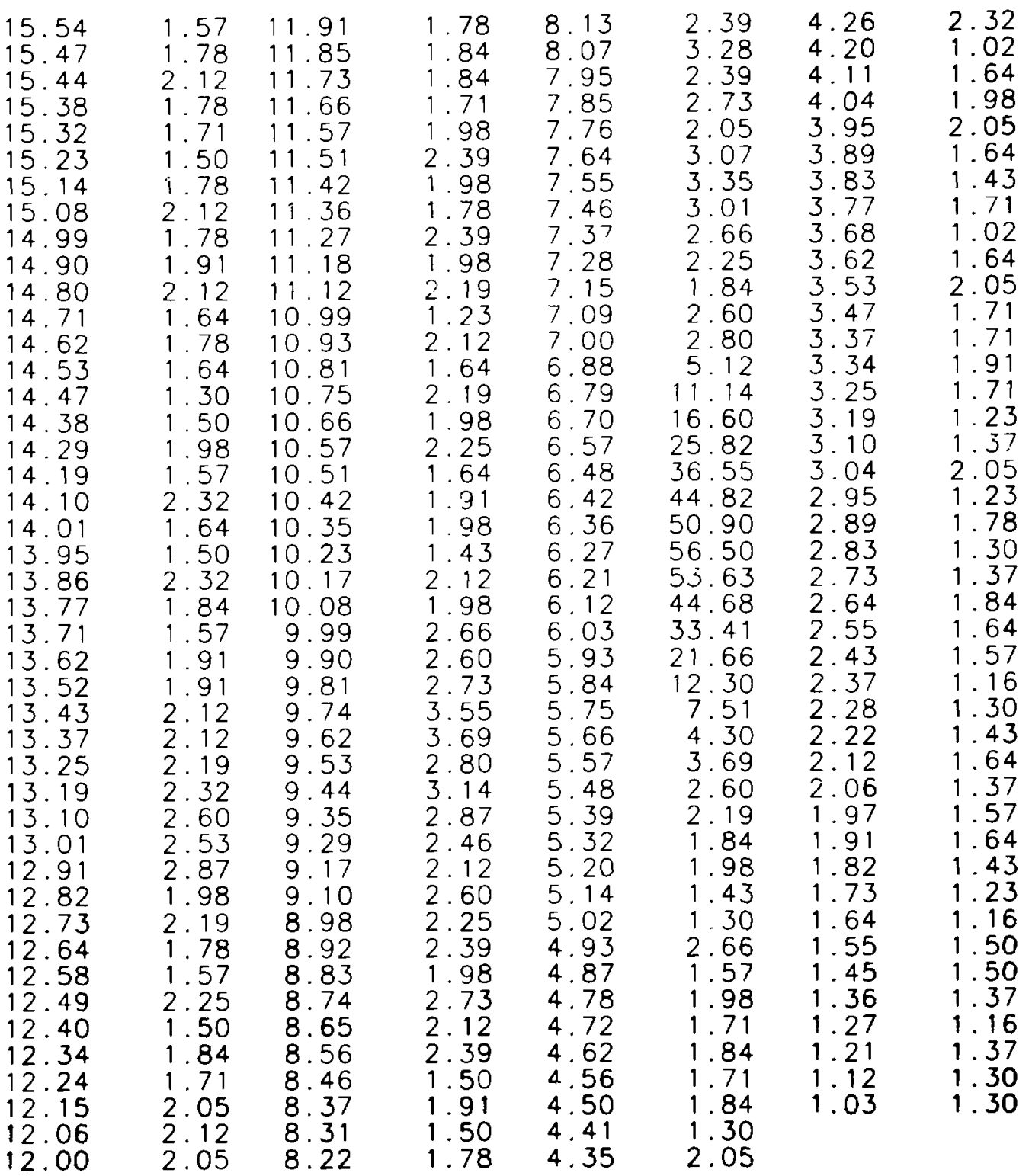




\section{Well 181 \\ See Figure 14 \\ Passive \\ 15 seconds per interval}

depth cnts/sec depth cnts/sec depth cnts/sec depth cnts/sec

$\begin{array}{lrrrrrrr}7.58 & .27 & 7.00 & .48 & 6.36 & 3.69 & 5.63 & .07 \\ 7.52 & 0.00 & 6.94 & .55 & 6.30 & 3.14 & 5.57 & .14 \\ 7.46 & .14 & 6.88 & .82 & 6.24 & 1.78 & 5.48 & .07 \\ 7.40 & .14 & 6.82 & 1.09 & 6.21 & 2.32 & 5.39 & .14 \\ 7.34 & 0.00 & 6.73 & 1.84 & 6.12 & 1.16 & 5.29 & 0.00 \\ 7.28 & 0.00 & 6.67 & 2.32 & 6.06 & .96 & 5.17 & 0.00 \\ 7.21 & .14 & 6.57 & 4.03 & 5.93 & .61 & 5.11 & .07 \\ 7.15 & .27 & 6.54 & 3.83 & 5.87 & .61 & 5.02 & .07 \\ 7.09 & .20 & 6.48 & 3.35 & 5.78 & .34 & 4.93 & 0.00 \\ 7.03 & .34 & 6.42 & 4.17 & 5.69 & .07 & 4.87 & 0.00\end{array}$




\section{We $\| 181$ \\ See Figure 15 \\ Active \\ 10 seconds per interval}

depth cnts/sec depth cnts/sec depth cnts/sec depth cnts/sec

$\begin{array}{rrrrrrrr}30.17 & 2.15 & 22.97 & 2.87 & 15.72 & 1.43 & 8.16 & 1.95 \\ 29.92 & 2.77 & 22.73 & 2.66 & 15.51 & 1.95 & 7.89 & 3.18 \\ 29.71 & 1.74 & 22.52 & 1.33 & 15.23 & 2.66 & 7.67 & 3.28 \\ 29.47 & 2.15 & 22.27 & 2.36 & 15.02 & 2.05 & 7.43 & 3.28 \\ 29.25 & 1.95 & 22.06 & 1.54 & 14.77 & 1.64 & 7.15 & 2.36 \\ 29.01 & 1.95 & 21.78 & 2.36 & 14.53 & 2.25 & 6.91 & 4.20 \\ 28.76 & 1.95 & 21.57 & 1.84 & 14.29 & 2.05 & 6.70 & 13.42 \\ 28.52 & 2.15 & 21.33 & 2.36 & 14.04 & 1.33 & 6.42 & 37.51 \\ 28.28 & 2.05 & 21.11 & 1.23 & 13.80 & 1.54 & 6.21 & 50.52 \\ 28.06 & 1.64 & 20.87 & 2.56 & 13.55 & 2.97 & 5.96 & 29.31 \\ 27.85 & 1.23 & 20.66 & .92 & 13.34 & 2.36 & 5.72 & 11.27 \\ 27.58 & 1.95 & 20.41 & 2.05 & 13.10 & 2.77 & 5.48 & 3.28 \\ 27.36 & 1.33 & 20.20 & 2.25 & 12.82 & 2.87 & 5.23 & 2.36 \\ 27.12 & 1.43 & 19.96 & 1.95 & 12.61 & 1.84 & 4.99 & 2.25 \\ 26.87 & 2.15 & 19.71 & 2.05 & 12.34 & 1.54 & 4.72 & 1.84 \\ 26.66 & 1.74 & 19.50 & 2.05 & 12.09 & 2.15 & 4.47 & 2.56 \\ 26.42 & 2.36 & 19.25 & 2.56 & 11.85 & 2.87 & 4.23 & 1.95 \\ 26.17 & 1.95 & 19.04 & 2.46 & 11.57 & 2.36 & 3.98 & 1.64 \\ 25.96 & 1.84 & 18.80 & 1.95 & 11.33 & 1.74 & 3.74 & 1.84 \\ 25.75 & 1.64 & 18.58 & 1.33 & 11.09 & 2.05 & 3.50 & 1.95 \\ 25.47 & 2.46 & 18.37 & 3.07 & 10.81 & 2.46 & 3.25 & 1.95 \\ 25.26 & 2.25 & 18.13 & 1.54 & 10.60 & 2.25 & 3.01 & 1.64 \\ 25.01 & 2.25 & 17.91 & 1.95 & 10.35 & 1.74 & 2.73 & 1.33 \\ 24.80 & 1.64 & 17.67 & 2.15 & 10.11 & 2.77 & 2.49 & 2.15 \\ 24.56 & 1.95 & 17.43 & 2.56 & 9.87 & 2.77 & 2.25 & 2.36 \\ 24.34 & 1.64 & 17.21 & 2.36 & 9.62 & 2.36 & 1.97 & 2.05 \\ 24.10 & 1.74 & 16.97 & 1.54 & 9.38 & 3.48 & 1.73 & 2.05 \\ 23.89 & 2.15 & 16.69 & 2.36 & 9.13 & 4.00 & 1.48 & 1.23 \\ 23.64 & 2.05 & 16.45 & 1.43 & 8.92 & 3.28 & 1.24 & 1.74 \\ 23.43 & 1.64 & 16.24 & 2.15 & 8.65 & 2.36 & 1.00 & 1.95 \\ 23.19 & 1.33 & 15.99 & 1.84 & 8.40 & 1.74 & .75 & 2.15\end{array}$

